\title{
Proposição de ferramenta de gestão pós-obra a partir dos registros de solicitação de assistência técnica
}

\author{
Proposal for a post-work management tool based on the \\ records of technical assistance requests
}

\section{Daniel Cupertino \\ Maria Carolina Gomes de Oliveira Brandstetter}

Resumo obra em empresas construtoras do mercado goiano e estudos de caso para aprofundamento das análises dos dados em duas empresas construtoras. Foram analisados mais de 3000 dados que permitiram uma análise discriminativa por categorias de serviços, uma proposta de análise da origem das manifestações patológicas, a proposição e aplicação da técnica FMEA e a construção e validação da ferramenta eletrônica para gestão dos dados de assistência técnica. Foi possível constatar que os principais serviços que geram solicitações de assistências técnicas no Pós-obra são os serviços de instalações hidrossanitárias. Entre as origens das ocorrências de solicitações de assistências técnicas observou-se que $44 \%$ das manifestações patológicas detectadas podem ser decorrentes da fase de execução do empreendimento. O FMEA permitiu identificar que as solicitações com prioridade de risco mais elevado são provenientes principalmente de solicitações referentes a revestimentos de parede e piso. A ferramenta eletrônica evidenciou a sistematização dos dados e evidenciou a importância de diversas análises possíveis a partir do correto registro das informações pós obra. A pesquisa contribui para a minimização da lacuna do conhecimento no que abrange a construção e validação de ferramentas que comprovam a importância da retroalimentação dos dados para as demais etapas do processo construtivo.

Palavras-chave: Gestão. Manutenção predial. Assistência técnica. FMEA.
Daniel Cupertino Universidade Federal de Goiás Goiânia - GO - Brasil

Maria Carolina Gomes de Oliveira Brandstetter Universidade Federal de Goiás Goiânia - GO - Brasil

Recebido em 16/03/15 Aceito em 03/08/15

\section{Abstract}

This study seeks to present the construction, application and validation of a management tool based on records of technical assistance requests. The methodology included a data survey in order to better understand post-work processes in construction companies, as well as case studies in two construction companies located in Goiania, GO, Brazil. More than 3,000 data allowed a discriminative analysis by service category, a proposal to analyse the pathologies' cause, an application of the FMEA technique and the construction and validation of an electronic tool for the management of technical assistance data. The services that generate the most technical assistance requests are the water/sanitary installations. About $44 \%$ of the pathological manifestations detected may have arisen from the execution. The FMEA identified that the requests with higher risk priority are mainly claims related to wall and floor coverings. The electronic tool showed the data systematization and the importance of various possible analyses based on the correct recording of post-work information.

Keywords: Management. Building maintenance. Technical assistance. FMEA. 


\section{Introdução}

A grande expansão da construção civil e o aumento da concorrência e dos níveis de exigência dos clientes foram fatores decisivos na mudança de mentalidade das empresas que visualizaram principalmente a busca pela máxima satisfação dos clientes e a melhoria contínua de seus processos produtivos como oportunidades de obter um diferencial de mercado e, consequentemente, sua permanência no mercado (FANTINATTI; GRANJA; MELO, 2007; BRITO, 2009; VAZQUEZ; SANTOS, 2010).

A busca pela implantação de sistemas de gestão não só focados na qualidade de seus produtos e na satisfação dos clientes, mas também no controle dos impactos ambientais gerados, na manutenção de um ambiente com riscos à saúde e segurança dos trabalhadores controlados e na atuação socialmente responsável são também focos a ser atingidos (ARDITI; NAWAKORAWIT, 1999; WACLAWOVSKY; BATIZ, 2010).

Mesmo as empresas que possuem um sistema de gestão da qualidade eficiente não estão imunes a falhas após a entrega da obra ao cliente. É necessário que exista um departamento para que os problemas pós-obra sejam corrigidos, ajudando a retroalimentar o sistema produtivo para se evitarem futuras solicitações de assistência técnica, propor ações preventivas e agregar custos ao produto final. O departamento pós-obra pode ser considerado como um elo entre a empresa e seu cliente na busca da qualidade e da satisfação das necessidades dos usuários internos e externos (FANTINATTI, 2008).

Em vários estudos pode ser observado que muito pouco se tem avançado quando se trata de assistência técnica nas empresas de construção civil (PICCHI, 2003; FANTINATTI, 2008; VAZQUEZ; SANTOS, 2010). Picchi (2003), em seu estudo de abordagem das oportunidades de implantação do Lean Thinking na construção, já apontava que existiam poucos estudos relacionados ao pós-obra em edificações, fato comprovado com a revisão bibliográfica feita neste estudo.

Fantinatti (2008) ressalta a falta de informações nacionais e internacionais relacionadas à assistência técnica em empresas de construção civil, e evidencia a importância da mudança de cultura das organizações e a busca por uma melhor gestão do conhecimento que as empresas ainda não possuem em relação às assistências técnicas por elas prestadas a seus clientes.

O problema visualizado como oportunidade na busca pela melhoria contínua dos processos da construção civil refere-se ao departamento pósobra, que, segundo Fong e Wong (2005), é um processo descontínuo, de curta duração, que não tem sido suficientemente valorizado (LIMA; CASTILHO, 2006), mas com muito espaço nos cenários nacional e internacional para evoluir.

Diante do exposto, segue a questão norteadora da pesquisa: como as solicitações de assistência técnica de uma empresa podem retroalimentar o sistema produtivo com informações que permitam melhorar continuamente seus processos e evitar a recorrência dos vícios construtivos e manifestações patológicas detectados?

O principal objetivo desta pesquisa consiste na proposição de uma ferramenta de gestão pós-obra a partir dos registros de solicitação de assistência técnica. Especificamente se buscou relacionar os principais vícios construtivos e manifestações patológicas detectadas a partir de dados de assistência técnica com suas possíveis origens; propor uma aplicação da técnica de análise de efeitos do modo de falhas (FMEA, Failure Mode and Effect Analysis) a partir de um banco de dados de assistências técnicas de empresas construtoras; e construir e validar o modelo eletrônico de gerenciamento de dados de assistência técnica para empresas de construção civil, no intuito de auxiliar na padronização dos registros e no armazenamento e tabulação das informações provenientes das solicitações dos clientes na fase do pós-obra.

Nas literaturas nacional e internacional a importância da retroalimentação de dados provenientes dos usuários já se encontra largamente difundida, porém as pesquisas geram modelos teóricos da sistematização dos dados ou se limitam na proposição de diretrizes de melhorias. A originalidade da pesquisa encontra-se na construção e validação de uma ferramenta de gestão a partir do emprego dos dados gerados durante a fase de uso e manutenção das edificações, além da aplicação inédita da técnica FMEA no âmbito da assistência técnica de edificações. Observa-se a lacuna existente de pesquisas que possam demonstrar o emprego de ferramentas de gestão que subsidiem o planejamento estratégico e comprovem a possibilidade de retroalimentação dos dados para as demais etapas e agentes do processo construtivo, consolidando a filosofia da melhoria contínua. 


\section{Síntese da fundamentação teórica}

A manutenção predial é classificada por diferentes enfoques, como pode ser observado nos Quadros 1 e 2 .

O Quadro 1 ressalta como vários autores classificam de modo diferente os tipos de manutenção predial. Outros enfoques de classificação dos tipos de manutenção são descritos por Gomide (2006). Por meio da Quadro 2 é possível observar uma síntese dessa classificação.

As múltiplas classificações salientam a importância do tema, cujo foco está na fase mais longa do ciclo de vida da edificação, a fase de uso e ocupação da edificação, que perdura décadas. Dessa forma, para se manter a vida útil de um empreendimento é necessário que ele sofra intervenções de manutenção a fïm de manter seu desempenho adequado (SANCHES, 2010).

A preocupação com as manifestações patológicas e os vícios construtivos das edificações está diretamente relacionada com as responsabilidades e com a legislação específica aplicada à construção civil, tais como o Código Civil em seu capítulo VIII, artigo 618 (BRASIL, 2005), e o Código de Defesa do Consumidor, os quais foram reforçados com a criação da norma NBR 15575 (ABNT, 2013) no que tange à avaliação do desempenho mínimo e vida útil relacionados à estrutura, instalações, revestimentos de piso e paredes, vedações e coberturas, entre outros.

Todas as construções necessitam de um planejamento de manutenções preventivas ao longo de sua vida útil, por mais bem planejada, projetada e executada que seja. Essas intervenções preventivas buscam, segundo a NBR 5674 (ABNT, 2012), preservar ou recuperar as condições funcionais adequadas ao uso previsto para as edificações, incluindo todos os serviços necessários para prevenir ou corrigir as perdas de desempenho geradas com o uso.

As intervenções têm o objetivo de elevar o patamar de desempenho das edificações, mesmo considerando quedas residuais e evitando a chegada da edificação ao patamar mínimo exigido (LICHTENSTEIN, 1986). Adiar uma intervenção pode significar o aumento dos custos diretos em progressão geométrica de razão cinco, como preconiza a Lei de Sitter ou Lei de Evolução de Custos (SITTER, 1984). O conhecimento de todas as possibilidades de problemas permite uma ação mais qualificada das intervenções, que podem ser feitas desde as etapas anteriores ao projeto até a pós-construção (LEONG; ZAKUAN; SAMAN, 2012).

Quadro 1 - Tipos de manutenção predial por autor

\begin{tabular}{|c|c|}
\hline BS 3811 British (1984) & $\begin{array}{l}\text { - Manutenção Planejada } \\
\text { - Manutenção Preventiva } \\
\text { - Manutencão de Rotina }\end{array}$ \\
\hline NBR 5462 (ABNT, 1994) & $\begin{array}{l}\text { - Manutenção Preventiva } \\
\text { - Manutenção Corretiva } \\
\text { - Manutencão Preditiva }\end{array}$ \\
\hline $\begin{array}{c}\text { Arditi e Nawakorawit } \\
\text { (1999) }\end{array}$ & $\begin{array}{l}\text { - Manutenção de Serviços } \\
\text { - Manutenção de Rotina } \\
\text { - Manutenção Preventiva } \\
\text { - Manutenção Corretiva } \\
\text { - Manutenção Adiada } \\
\text { - Manutenção Extraoordinária }\end{array}$ \\
\hline $\begin{array}{l}\text { Siqueira }(2005) \text { e } \\
\text { Dardengo }(2010)\end{array}$ & $\begin{array}{l}\text { - Manutenção Corretiva } \\
\text { - Manutenção Preventiva } \\
\text { - Manutenção Preditiva } \\
\text { - Manutenção Proativa } \\
\text { - Manutenção Produtiva } \\
\text { - Manutenção Detectiva }\end{array}$ \\
\hline Kardec e Nascif (2006) & $\begin{array}{l}\text { - Manutenção Corretiva não Planejada } \\
\text { - Manutenção Corretiva Planejada } \\
\text { - Manutenção Preventiva } \\
\text { - Manutenção Preditiva } \\
\text { - Manutenção Detectiva } \\
\text { - Manutenção de Manutenção }\end{array}$ \\
\hline Gomide (2006) & $\begin{array}{l}\text { - Manutenção Preventiva } \\
\text { - Manutenção Preditiva } \\
\text { - Manutenção Corretiva }\end{array}$ \\
\hline
\end{tabular}


Quadro 2 - Classificação das atividades de manutenção

\begin{tabular}{|c|l|}
\hline $\begin{array}{c}\text { Quanto à viabilidade dos serviços de } \\
\text { manutenção }\end{array}$ & - Técnica \\
& - Uso e operacional \\
& - Administrativa ou de custos e responsabilidade \\
\hline Quanto às falhas e anomalias & - Falhas de planejamento \\
existentes & - Falhas de execução \\
& - Falhas operacionais \\
& - Falhas gerenciais \\
\hline Quanto ao tipo de intervenção & - Conservação \\
& - Recuperação \\
& - Restauração \\
\hline Quanto à periodicidade de & - Modernização \\
\hline realização das atividades & - Rotineiras \\
& - Periódicas \\
& - Emergenciais \\
\hline
\end{tabular}

Fonte: Gomide (2006).

Em sua pesquisa, Fantinatti (2008) conclui apontando a importância do compartilhamento e reutilização do conhecimento a partir das atividades de assistência técnica em um empreendimento, e Brito (2009), estudando a retroalimentação do conhecimento de falhas construtivas em empreendimentos de habitação de interesse social a partir de reclamações dos usuários, propõe uma estrutura para o gerenciamento de reclamações, com a retroalimentação do sistema e o feedback ao usuário final. Ambos os autores sugerem a aplicação dos dados provenientes da grande etapa de uso e manutenção na geração de melhoria contínua dos processos para novos empreendimentos.

Entre as informações primordiais para tal ciclo de melhoria estão as análises das origens dos problemas patológicos, que abrangem uma literatura vasta no âmbito dos processos construtivos. Alguns estudos somente trataram de uma investigação que buscasse categorizar tais origens por meio das grandes fases de uma edificação: planejamento, projeto, materiais, execução e uso/manutenção. Entre estes apontamse o de Henriques (2001), Helene e Pereira (2007), Ferreira (2009) e Fiess et al. (2004), os quais destacaram a fase relacionada aos projetos como preponderante para a ocorrência de manifestações patológicas. Outros trabalhos internacionais também relacionaram o projeto como causa maior das falhas em edificações, como o estudo de Lam (2000 ${ }^{1}$ apud DAS; CHEW, 2011), em Hong Kong, a pesquisa de Chong e Low (2006), em Singapura, e Chew, Silva e Tan (2003), que também corroboraram a identificação do projeto (design) como preponderante nas falhas sobre a execução, o uso e a condição ambiental.

${ }^{1}$ LAM, K. C. Quality Assurance in Management of Building Services Maintenance. Southeast Asia Facility Management Journal, may/jun, 2000.
Quanto aos estudos que trataram dos métodos gerenciais utilizados para a detecção de modos de falhas dos sistemas na busca pela melhoria contínua dos processos, o FMEA alcançou sucesso pautado na qualidade e no planejamento estratégico. Corresponde a uma técnica que analisa cada modo de falha de um sistema específico visando determinar as consequências ou os efeitos dessas falhas em outros sistemas, classificando assim cada modo de falha de acordo com sua severidade, ocorrência e detecção, e recomendando ações para eliminar ou minimizar seus efeitos (PUENTE et al., 2002; RHEE; ISHII, 2003; AGUIAR, 2007; LAURENTI, 2010). Fernandes (2005) e Aguiar (2007) salientam que o FMEA é um método analítico que segue uma sequência lógica e sistemática, usada para detectar e eliminar falhas potenciais encontradas em sistemas ou processos de fabricação.

A análise FMEA pode ser enquadrada em dois tipos básicos: o FMEA de produto e o FMEA de processo. Verificou-se que esta técnica está mais difundida na indústria automobilística, aeroespacial e eletrônica, mas que também pode ser utilizada na indústria da construção civil em diferentes fases e níveis da empresa, como, por exemplo, a fase de planejamento, concepção de projeto, execução e pós-obra, visando à otimização e melhoria dos processos (TOZZI, 2004; PEREIRA, 2008; MIGUÉIS, 2010; SILVA; FONSECA; BRITO, 2006). A análise FMEA deve ser feita de forma cíclica em todas as fases da obra, assumindo um papel preventivo na fase de projeto e um papel dinâmico na fase de execução das tarefas (MIGUÉIS, 2010; BAHRAMI; BAZZAZ; SAJJADI, 2012).

Foi feita uma análise sistemática da literatura internacional no que concerne à manutenção de edifícios e à aplicação da técnica FMEA. A análise envolveu mais de cem artigos científicos com destaque para os periódicos Journal of 
Management in Engineering, Journal of Architectural Engineering, Journal of Construction Engineering and Management Facilities e Journal of Performance of Constructed Facilities, com recorte temporal das três últimas décadas. $\mathrm{Na}$ extração sistematizada de dados foi encontrado um único estudo exploratório de aplicação do FMEA a partir de dados da assistência técnica, porém sem descrição da construção ou validação da técnica (SOUZA, 2013). Cabe destacar os estudos que combinaram a técnica FMEA com Lógica Fuzzy e AHP (Analytic Hierarchy Process) para análise de riscos de projetos como o trabalho de Abdelgawad e Fayek (2010) e El-Haram e Horner (2003), que discutiram o potencial do FMEA e avaliação de riscos na seleção de melhores estratégias para o ciclo de vida da edificação, e o trabalho de Das e Chew (2011), que aplicou o FMECA para análise de riscos, porém sem utilizar dados de assistência técnica.

\section{Método de pesquisa \\ Delineamento da pesquisa}

A pesquisa busca apresentar a ferramenta de gestão dos dados pós-obra, buscando exemplificar como eles podem ser mais bem analisados a partir de um registro eficiente quanto à solicitação da assistência técnica. Para a construção dessa ferramenta, a pesquisa buscou inicialmente investigar a forma como os registros são realizados nas empresas construtoras. Paralelamente foram propostas análises dos dados pós-obra visando identificar quais informações seriam necessárias para apoiar a gestão no que tange à melhoria contínua de seus processos e produtos.

Para que o levantamento de dados da pesquisa fosse possível foi identificada no mercado goiano uma amostra não probabilística intencional, definida pela abertura disponibilizada pelas empresas na obtenção dos dados necessários para a realização do trabalho, contendo oito empresas consolidadas de médio e grande porte que atendiam aos seguintes requisitos: possuir certificações NBR ISO 9001 e PBQP-H Nível A, atuar no mercado há mais de dez anos no setor da construção civil diretamente no ramo de construções de empreendimentos habitacionais multifamiliares verticais e possuir um banco de dados de solicitações de assistência técnica. Buscaram-se empresas cujos campos de atuação eram similares, ou seja, atuavam no mesmo segmento de mercado.

A partir da identificação das empresas participantes da pesquisa os dados coletados foram obtidos de forma direta e indireta juntamente com o corpo gerencial das empresas. Buscou-se traçar o perfil de gestão da qualidade das informações coletadas das assistências técnicas prestadas por meio de entrevistas e pesquisa documental. Essa etapa buscou mapear a rotina do departamento pós-obra da construtora, como as informações das assistências técnicas prestadas aos clientes eram registradas e se existia alguma forma de retroalimentação dos dados obtidos.

Em etapa posterior duas empresas entre as oito participantes (empresas A e D) foram escolhidas para a realização do estudo de caso, levando em consideração principalmente o maior acesso e o interesse delas em participar da pesquisa, visando à melhoria contínua de seus procedimentos. Os estudos visaram a uma análise mais aprofundada das formas de registros e análise das solicitações de assistências técnicas para a proposição da ferramenta de gestão objetivada pela pesquisa.

A Figura 1 ilustra o fluxograma de delineamento das principais etapas da pesquisa.

Cabe salientar que o modelo eletrônico de gerenciamento de dados de assistência técnica, o qual constitui a ferramenta de gestão apresentada na pesquisa, busca reunir as três principais análises dos dados que fizeram parte da metodologia: a análise quantitativa dos registros por categorias de serviços; a análise da origem das manifestações patológicas; e a análise dos riscos por meio da técnica FMEA, mediante uma adaptação de seus parâmetros para a construção civil. Segue a instrumentação da coleta e análise dos dados.

\section{Análise quantitativa dos registros de assistência técnica por categoria}

A coleta de dados nas empresas participantes dos estudos de caso foi realizada por meio dos registros de assistências técnicas disponibilizados pelas empresas. Como necessidade preliminar na avaliação da solicitação feita pelo usuário viu-se necessário entender os motivos da procedência ou improcedência da solicitação.

As empresas participantes dos estudos de caso possuíam formas diferentes de registros. A empresa A realiza o registro de suas informações de solicitações de assistências técnicas em um software de Customer Relationship Management (CRM). A coleta foi realizada por meio do acesso a todas as solicitações de assistências técnicas atendidas pela empresa em quatro anos, entre 2008 e 2011, buscando identificar possíveis causas e subcausas dos problemas detectados. Foram analisadas $\quad 1.457 \quad$ solicitações em 13 empreendimentos. 
Figura 1 - Etapas da pesquisa

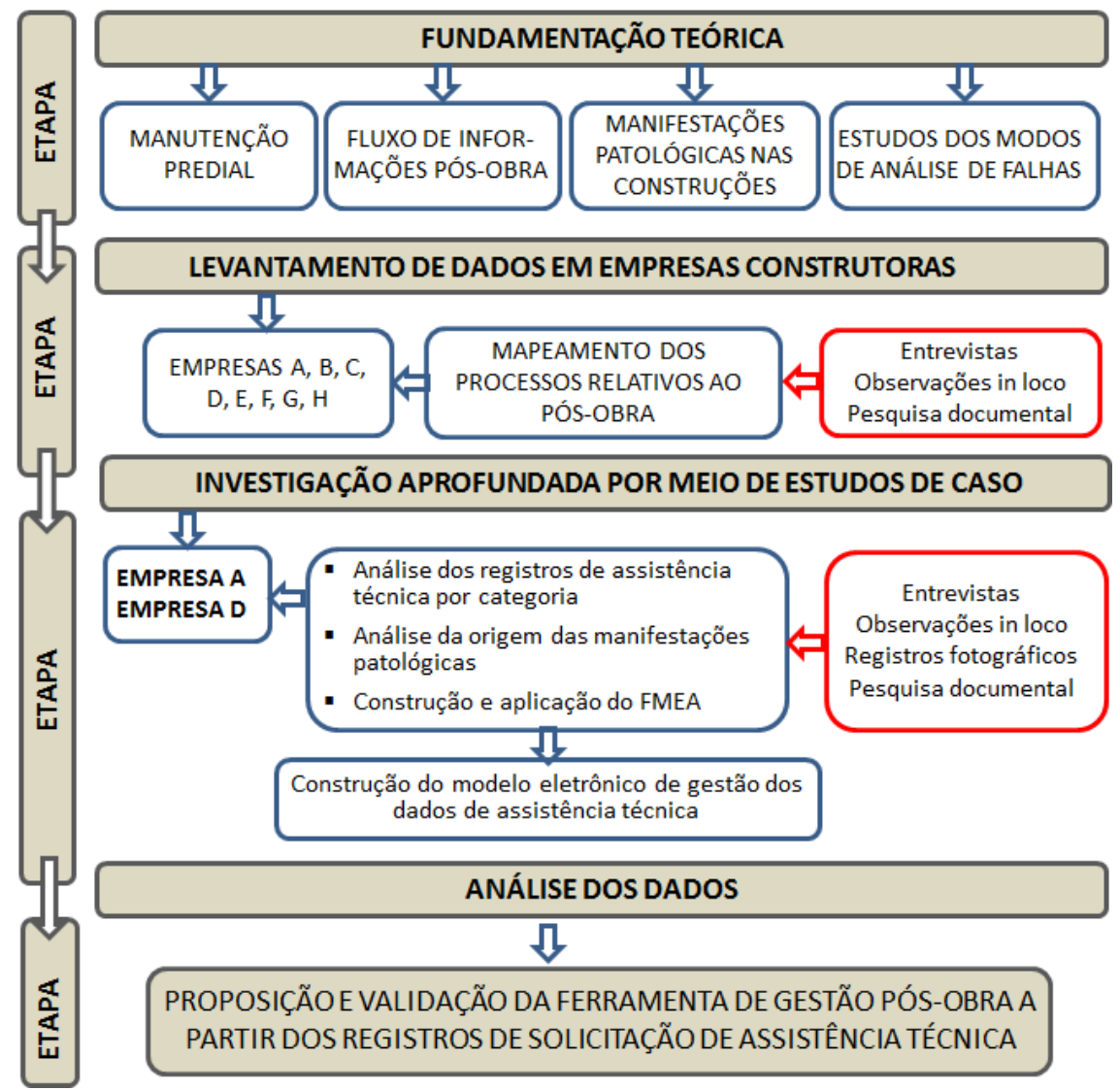

Na empresa D foi desenvolvido um formulário padrão para registrar os atendimentos de solicitações de assistências técnicas, constituídos por fichas de solicitação e ordem de serviço. O preenchimento das fichas é feito de forma manual, todas armazenadas de forma impressa, e o gerenciamento das informações é feito por meio da tabulação dos dados em planilha eletrônica. Como todos os registros foram realizados de forma manual, tornou-se necessária a digitalização de todos os formulários relativos à assistência técnica. Foram analisadas 1.607 solicitações em 11 empreendimentos.

Ambas as empresas A e D atuam no segmento de edificações residenciais multipavimentos. Todos os empreendimentos considerados nas análises das solicitações de assistência técnica foram escolhidos por possuir similaridade em termos de tecnologias construtivas e atender ao mesmo macrossegmento de mercado (área privativa entre 70 e $120 \mathrm{~m}^{2}$, bairros centralizados na capital goiana e semelhante padrão de acabamento).

Cada ficha de solicitação de assistência técnica preenchida pelas empresas foi analisada, e as causas das solicitações contidas nas ordens de serviço foram agrupadas conforme suas semelhanças em serviços macro. A organização dos dados em planilha permitiu a categorização dos dados também em função dos empreendimentos (tempo de entrega, tipologia padrão, especificação da unidade de apartamento por andar) e data do registro da solicitação, além de possíveis custos registrados.

\section{Análise da origem das manifestações patológicas}

Esta análise foi motivada pela possibilidade de confirmação dos dados já largamente divulgados em outros estudos - porém nenhum no cenário nacional -, que estabeleceram as maiores causas das manifestações patológicas proporcionadas por falhas ocorridas na fase de projeto, seguidas por falhas na execução. A análise também foi oportunizada pelo fato de se ter um banco de dados contemplando todos os tipos de possíveis falhas detectadas na grande etapa de uso e manutenção das edificações, que juntos somavam acima de 3.000 registros.

Considerando todo o universo de solicitações, foi feita uma análise prévia para determinar as mais recorrentes entre todos os dados coletados. Foram listadas 63 solicitações mais recorrentes nos 
serviços de instalações hidráulicas, esquadrias, revestimento de parede, revestimento de piso, instalações elétricas, pintura, forro de gesso e revestimento de teto. A partir dessa listagem foi desenvolvido um questionário, considerando cada problema de forma individual, conforme ilustrado na Figura 2.

Para a análise e preenchimento foram convidados profissionais que atuavam diretamente na execução de obras e especialistas de cada um dos serviços envolvidos para que fosse realizada uma análise crítica das manifestações patológicas e, posteriormente, com o auxílio da vivência e experiência de cada um, atribuíssem porcentagens correspondentes às possíveis origens das manifestações patológicas. Ressalta-se a limitação em termos do método empregado nesta análise devido à indisponibilidade de informações nos registros dos sistemas de gestão das construtoras, que pudessem ser associadas às origens das manifestações patológicas detectadas durante a etapa de uso das edificações. A identificação dessa limitação de informações foi fundamental para a construção da ferramenta de gestão proposta pela pesquisa.

\section{Construção e aplicação da técnica FMEA no pós-obra}

Buscou-se realizar uma adaptação dos parâmetros analisados pelo FMEA, os quais usualmente empregam os índices de severidade, ocorrência e detecção. Foram propostos outros índices que pudessem melhor retratar o índice de criticidade no âmbito da construção. Foram propostas as escalas de valoração identificando a severidade do modo de falhas " $S$ ", o custo necessário para corrigir a falha " $C$ " e a complexidade de intervenção da falha "I". Para a análise de criticidade das manifestações patológicas detectadas foi proposto o cálculo dos coeficientes de prioridade de risco "CPR=S*C*I".

\section{Severidade}

A valoração da severidade visa avaliar o impacto causado pelo efeito do modo de falha sobre o funcionamento do dispositivo que está sendo analisado. Foi atribuída uma escala de 1 a 4 na atribuição da valoração de "S", conforme pode ser observado no Quadro 3.

\section{Custo}

Buscou-se respaldar os custos de manutenção predial em edificações na literatura. Marques de Jesus (2008) faz um estudo de reabilitação em cinco edifícios na cidade de São Paulo, levantando os custos globais necessários para reabilitar os edifícios estudados. Vazquez e Santos (2010) levantaram os custos anuais com os serviços de assistência técnica necessários para o tratamento das patologias separando os custos por subsistemas de construção. Em relação às intervenções realizadas de forma pontual, como é o caso das intervenções devido às solicitações de assistências técnicas, ainda não foram encontrados estudos referentes aos custos necessários para restabelecer a funcionalidade das edificações.

\section{Figura 2 - Trecho do questionário para identificação da origem das manifestações patológicas no pós-} obra

\begin{tabular}{|c|c|c|c|c|c|c|c|c|}
\hline \multicolumn{9}{|c|}{$\begin{array}{l}\text { Instruções para preenchimento } \\
\text { estimadas em conformidade con } \\
\text { Exemplo do preenchimento: }\end{array}$} \\
\hline \multirow[b]{2}{*}{ Item } & \multirow[t]{2}{*}{+2} & \multirow[b]{2}{*}{ Situação encontrada - Descrição da Patologia } & \multicolumn{5}{|c|}{ Origem da causa (\%) } & \multirow[b]{2}{*}{ ङूँ } \\
\hline & & & $\frac{\circ}{\frac{2}{2}}$ & 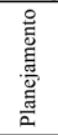 & 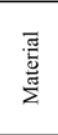 & 胥 & 号 & \\
\hline 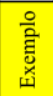 & Esquadria & Porta empenada & $0 \%$ & $10 \%$ & $60 \%$ & $20 \%$ & $10 \%$ & $100 \%$ \\
\hline & & & & & & & & \\
\hline 1 & Instalações Hidráulicas & $\begin{array}{l}\text { Peças hidráulicas (torneira e registros) pingando sem parar ou estão } \\
\text { espanados }\end{array}$ & & & & & & $0 \%$ \\
\hline 2 & Instalações Hidráulicas & $\begin{array}{l}\text { Caixas acopladas não estão funcionando, com baixa pressão ou } \\
\text { fazendo barulho }\end{array}$ & & & & & & $0 \%$ \\
\hline
\end{tabular}


Quadro 3 - Índices de severidade

\begin{tabular}{|c|l|l|}
\hline Índice & Severidade & \multicolumn{3}{|c|}{ Critério } \\
\hline 1 & Pequena & $\begin{array}{l}\text { Ligeira deterioração ou queda no desempenho do sistema com leve } \\
\text { descontentamento do cliente }\end{array}$ \\
\hline 2 & Moderada & $\begin{array}{l}\text { Deterioração significativa no desempenho do sistema com } \\
\text { descontentamento do cliente }\end{array}$ \\
\hline 3 & Alta & Sistema deixa de funcionar gerando grande descontentamento do cliente \\
\hline 4 & Muito Alta & $\begin{array}{l}\text { Sistema deixa de funcionar gerando grande descontentamento do cliente e } \\
\text { afetando a segurança do mesmo }\end{array}$ \\
\hline
\end{tabular}

Fonte: adaptado de Pereira (2008).

Por ainda não haver parâmetros definidos em relação ao custo, foi proposta uma forma de quantificar esse critério. A valoração do custo gerado por cada intervenção busca relacionar os gastos necessários para correções futuras em empreendimentos. Foi proposta uma escala de 1 a 4, cujas faixas foram baseadas na análise do banco de dados da empresa D. Foram selecionadas 726 solicitações de assistência técnica em que os custos com as reparações estavam registrados de modo mais detalhado no formulário. Todos os dados foram tabulados em planilha eletrônica conforme a sequência:

(a) os dados dos custos foram registrados em planilha eletrônica separados por ano e empreendimento de cada solicitação;

(b) foram levantadas as médias dos valores do INCC dos anos de 2007 a 2012 (período de ocorrência das solicitações) para realizar o reajuste dos valores das assistências técnicas prestadas;

(c) todos os dados foram reajustados e colocados em ordem crescente de custos, com suas respectivas porcentagens unitárias e acumuladas;

(d) como a escala proposta contempla 4 faixas de valores, identificou-se os valores mínimo e máximo a cada $25 \%$ dos valores registrados; e

(e) procedeu-se ao arredondamento dos valores.

A Tabela 1 apresenta a proposta para o critério custo.

\section{Complexidade de intervenção}

Pedro, Vilhena e Paiva (2011), em seu estudo no desenvolvimento de uma metodologia para avaliação da necessidade de reabilitação de edifícios, propuseram uma análise baseada na complexidade de intervenção dos problemas detectados. Nesse estudo a complexidade de intervenção se refere à reabilitação de edifícios e está enquadrada em três escalas (simples, média e difícil). Dessa forma, realizou-se uma adaptação da metodologia desenvolvida por Pedro, Vilhena e Paiva (2011) visando melhor enquadramento no que se estende às solicitações de assistências técnicas.

A complexidade de intervenção "I" também foi criada em uma escala variando de 1 a 4 , apresentada no Quadro 4, onde são indicados os atributos para cada índice valorado.

\section{Coeficiente de prioridade de risco}

O coeficiente de prioridade de risco visualizando o grau de risco da manifestação patológica identificada pode ser valorado por meio da multiplicação dos índices de severidade, custo e complexidade de intervenção, segundo a Equação 1. Dessa forma é possível atribuir faixas de prioridade de risco, conforme apresentado no Quadro 5, para se realizar um melhor plano de intervenção para empreendimentos futuros.

$\mathrm{CPR}=\mathrm{S} * \mathrm{C} * \mathrm{I}$

Eq. 1

Onde:

CPR: coeficiente de prioridade de risco;

$\mathrm{S}$ : índice de severidade;

C: índice de custo; e

I: índice de complexidade de intervenção.

\section{Construção e validação da ferramenta eletrônica de gestão dos dados}

Paralelamente à condução dos estudos de caso realizados foi elaborada uma ferramenta eletrônica visando propor um formato de registro mais completo das informações relevantes relativas à assistência técnica, aumentando a transparência e o controle dos serviços. 
Tabela 1 - Índices de custo

\begin{tabular}{|l|l|l|}
\hline Índice & \multicolumn{1}{|c|}{ Custo } & \multicolumn{1}{c|}{ Critério } \\
\hline 1 & Pequeno & Gastos entre $\mathrm{R} \$ 0,01$ a R\$ 450,00 \\
\hline 2 & Moderado & Gastos entre R\$ 451,00 a R\$ 1300,00 \\
\hline 3 & Alto & Gastos entre R\$ 1301,00 a R\$ 3000,00 \\
\hline 4 & Muito Alto & Gastos acima de R \$ 3001,00 \\
\hline
\end{tabular}

Quadro 4 - Índices de complexidade de intervenção

\begin{tabular}{|c|l|l|}
\hline Índice & $\begin{array}{l}\text { Complexidade } \\
\text { de Intervenção }\end{array}$ & \multicolumn{1}{c|}{ Critério } \\
\hline 1 & Simples & $\begin{array}{l}\text { Intervenção realizada em uma única operação ou pontual do sistema sem a } \\
\text { necessidade de intervenção em outros sistemas }\end{array}$ \\
\hline 2 & Média & $\begin{array}{l}\text { Intervenção moderada do sistema podendo ou não ter a necessidade de } \\
\text { intervenção em outro sistema gerando pequenas correções no mesmo }\end{array}$ \\
\hline 3 & Difícil & $\begin{array}{l}\text { Intervenção significativa do sistema com a necessidade de intervenção em } \\
\text { outros sistemas gerando demolição do sistema para correções e reexecução } \\
\text { do mesmo }\end{array}$ \\
\hline 4 & Muito Difícil & $\begin{array}{l}\text { Intervenção significativa do sistema com a necessidade de intervenção em } \\
\text { mais de um sistema gerando quebra, reexecução, reforços estruturais ou } \\
\text { reabilitação dos mesmos }\end{array}$ \\
\hline
\end{tabular}

Fonte: adaptado de Pedro, Vilhena e Paiva (2011).

Quadro 5 - Escala de valoração da prioridade de risco e grau de urgência das intervenções

\begin{tabular}{|c|c|c|}
\hline $\begin{array}{c}\text { Prioridade de } \\
\text { Risco }\end{array}$ & $\begin{array}{c}\text { Intervalo de } \\
\text { Valores }\end{array}$ & \multicolumn{1}{c|}{ Grau de urgência das intervenções } \\
\hline Baixo & $\mathrm{CPR} \leq 4$ & $\begin{array}{l}\text { Devem ser tomadas medidas de intervenções para melhoria sem } \\
\text { caráter de urgência }\end{array}$ \\
\hline Moderado & $4<\mathrm{CPR} \leq 16$ & $\begin{array}{l}\text { Devem ser tomadas medidas de intervenções logo que possível, } \\
\text { visando diminuir a probabilidade de ocorrência dos danos em } \\
\text { empreendimentos futuros }\end{array}$ \\
\hline Elevado & $16<\mathrm{CPR} \leq 32$ & $\begin{array}{l}\text { Devem ser tomadas medidas corretivas visando eliminar as } \\
\text { causas das manifestações patológicas detectadas, evitando a } \\
\text { ocorrência das mesmas em empreendimentos futuros }\end{array}$ \\
\hline Muito Elevado & $32<\mathrm{CPR} \leq 64$ & $\begin{array}{l}\text { Requer ações corretivas imediatas para eliminação das causas, } \\
\text { com análise crítica das etapas que se relacionam com o serviço } \\
\text { e controle, para que tais manifestações patológicas não ocorram } \\
\text { em empreendimentos futuros }\end{array}$ \\
\hline
\end{tabular}

Fonte: adaptado de Pereira (2008).

Com o uso das planilhas a empresa conseguirá registrar as solicitações dos clientes, acompanhar todas as etapas de execução dos serviços prestados e registrar os custos provenientes de cada solicitação, a equipe necessária para cada tipo de atividade e a pesquisa de satisfação do cliente. Empregaram-se os conceitos de um semáforo Poka-Yoke (ZÁRATE et al., 2011), uma ferramenta à prova de erros, de aplicação na filosofia Lean, no intuito de facilitar a visualização das etapas executadas. A ferramenta foi validada, para comprovação de sua aplicabilidade, empregando-se os dados registrados em uma das empresas do estudo de caso, a empresa D.

\section{Análise dos dados}

\section{Análise quantitativa dos registros de assistência técnica por categoria}

$\mathrm{Na}$ empresa A foi possível constatar que no período de quatro anos foram abertas 1.457 solicitações de assistências técnicas, totalizando 333 solicitações improcedentes e 1.124 
procedentes em 13 empreendimentos. O Gráfico de Pareto é ilustrado na Figura 3.

Com o auxílio do levantamento dos dados nas fichas de solicitações preenchidas pela empresa A foi constatado que $79 \%$ das solicitações procedentes são referentes a apenas cinco grupos de serviços, sendo eles $28 \%$ instalações hidrossanitárias, $17 \%$ revestimento de paredes, $14 \%$ esquadrias - portas, $10 \%$ revestimento de piso e $10 \%$ instalações elétricas.

Observou-se que existem alguns pontos a ser melhorados na empresa A, e foi verificada, em um primeiro momento, a existência de registros de vários serviços/ocorrência que deveriam ter sido filtrados no momento do preenchimento da solicitação do usuário. Tal procedimento, se utilizado, poderia direcionar o processo de uma forma melhor, evitando assim gastos de tempo para as equipes que interviriam no processo.

Assim foi possível observar que o treinamento das equipes envolvidas desde o atendimento do cliente até a pesquisa de satisfação é um ponto muito importante para que os registros sejam realizados de forma que possam ser utilizados em empreendimentos futuros.

No segundo caso estudado, constatou-se que na empresa $\mathrm{D}$, em um período de quatro anos, entre 2008 e 2011, foram abertas 1.607 solicitações de assistências técnicas, totalizando 444 solicitações improcedentes e 1.163 solicitações procedentes em 11 empreendimentos. O Gráfico de Pareto, ilustrado na Figura 4, compreende as solicitações coletadas.

Com o levantamento dos dados nas fichas de solicitações preenchidas pela empresa $\mathrm{D}$ foi constatado que $80 \%$ das solicitações procedentes são referentes a apenas cinco grupos de serviços, sendo eles $27 \%$ esquadrias - portas; $19,3 \%$ instalações hidrossanitárias, $13,9 \%$ revestimento de piso, $11,4 \%$ revestimento de parede e $8 \%$ instalações elétricas. Esses cinco grupos também foram os de maior incidência de ocorrências procedentes para o caso A.

\section{Análise dos resultados quanto à origem das manifestações patológicas}

O comparativo entre os resultados encontrados para a análise da origem das manifestações patológicas nos estudos realizados e os trabalhos de Henriques (2001), Ferreira (2009), Helene e Pereira (2007) e Fiess et al. (2004) pode ser visualizado no gráfico da Figura 5.

Diante do resultado obtido foi possível observar que houve variações em relação aos dados encontrados na literatura. Segundo Henriques (2001), Helene e Pereira (2007), Ferreira (2009) e Fiess et al. (2004), cerca de $40 \%$ a $50 \%$ das manifestações patológicas são provenientes das etapas de projetos, mas, segundo análise feita nas solicitações de assistências técnicas, a etapa de projeto corresponde a cerca de $9 \%$ dessas origens.

Figura 3 - Gráfico de Pareto das assistências técnicas procedentes - Empresa A

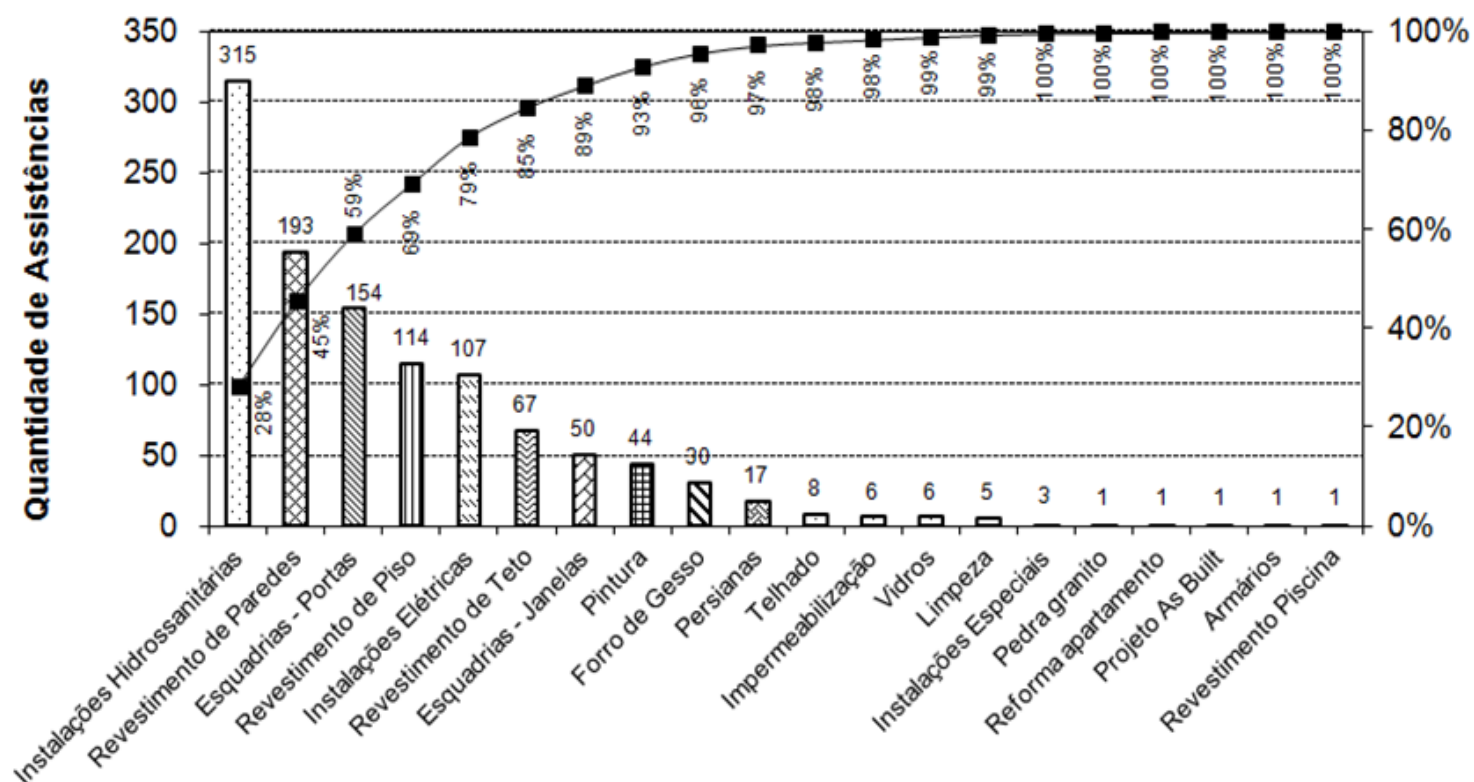

Serviços

252 Cupertino, D.; Brandstetter, M. C. G. de O. 
Figura 4 - Gráfico de Pareto das assistências técnicas procedentes - Empresa D

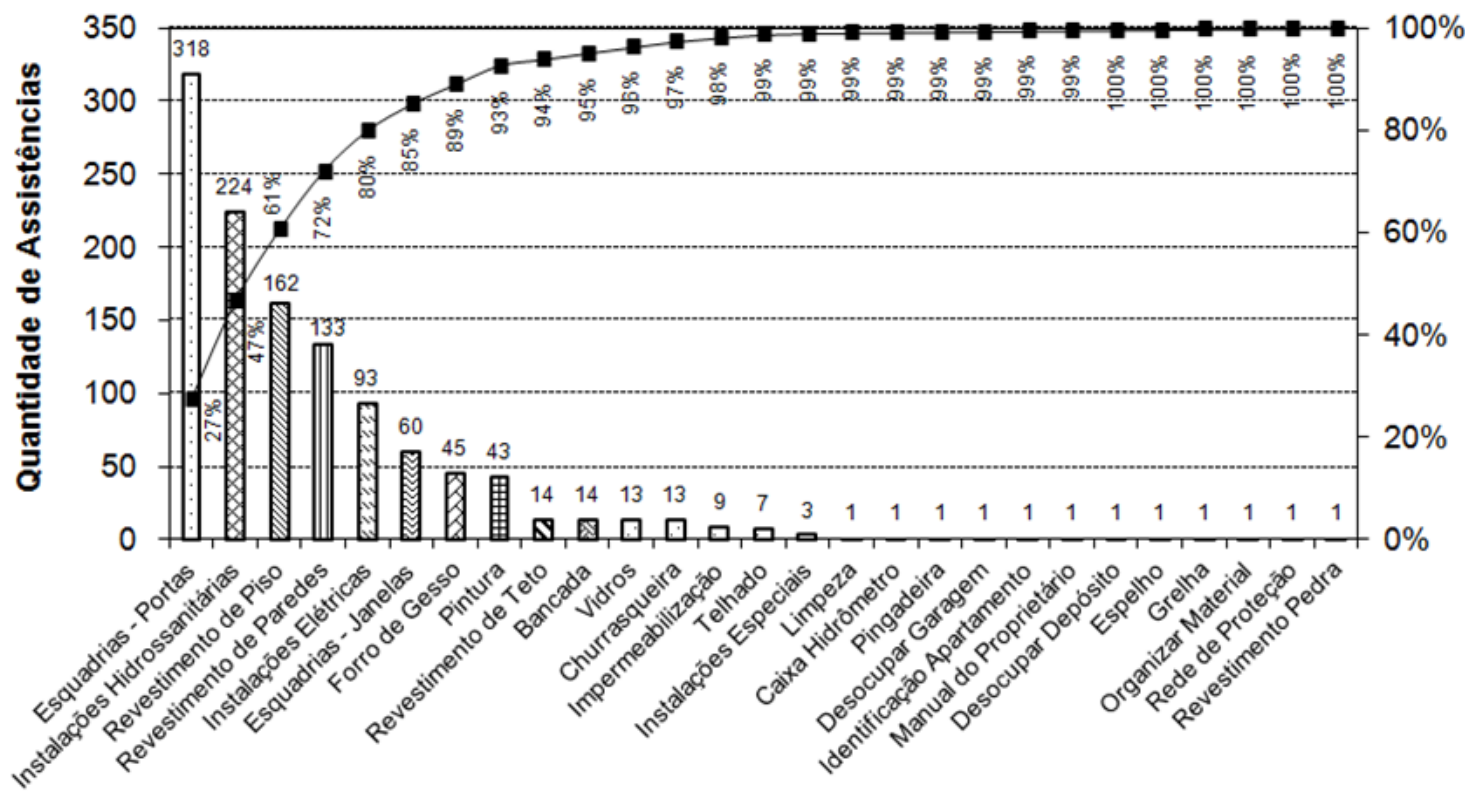

Serviços

Figura 5 - Origem das manifestações patológicas nas construções com relação às etapas de produção

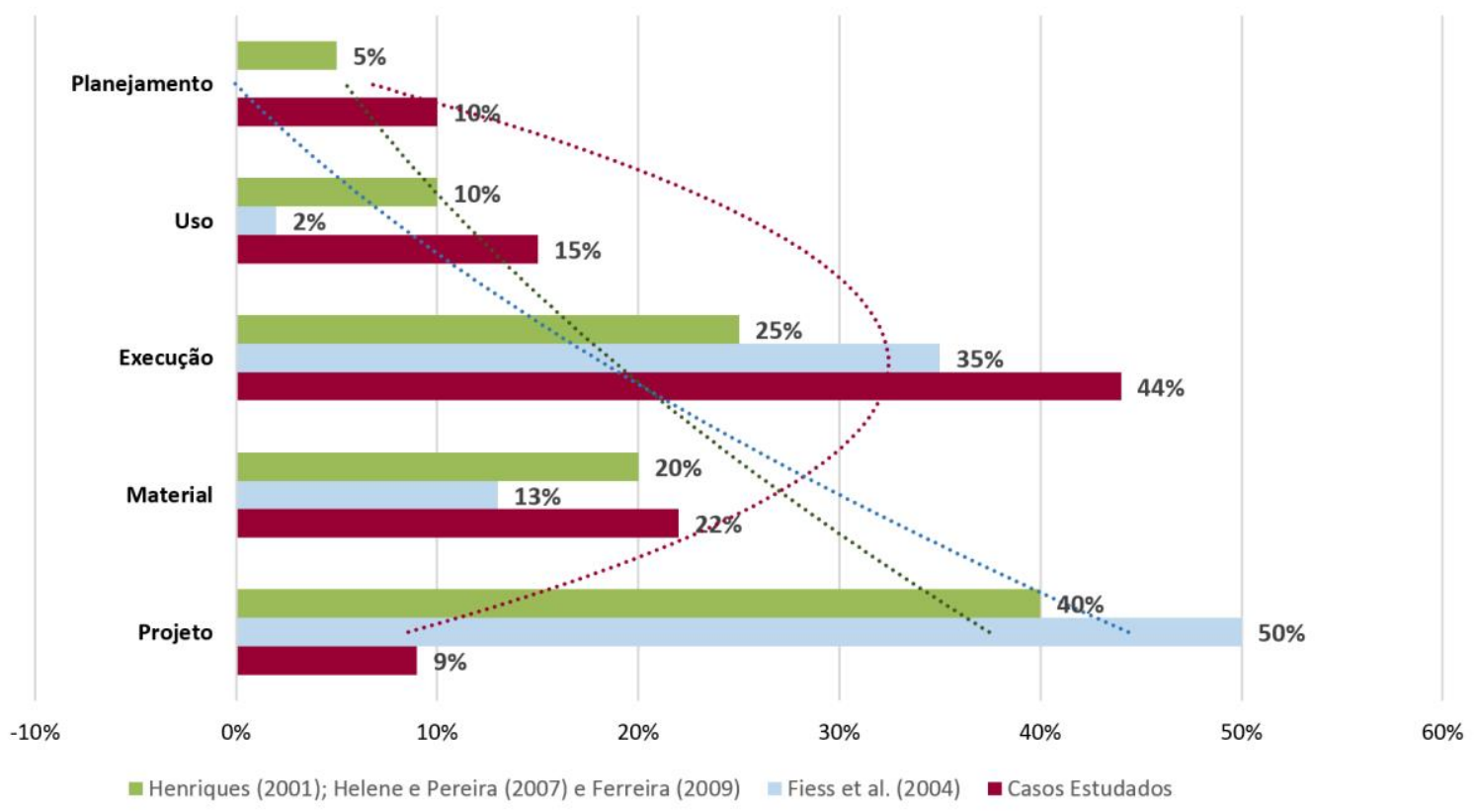

Na etapa de execução os percentuais da origem das manifestações patológicas, segundo a literatura estudada, estão entre $25 \%$ e $35 \%$ das ocorrências; já no caso das assistências técnicas estudadas a etapa de execução corresponde a cerca de $44 \%$ das ocorrências. Cabe ressaltar que parte das falhas ocorridas na etapa de execução pode estar vinculada à etapa de projeto, porém essa correlação se torna mais propícia a partir da análise de registros de assistência técnica mais completos, cujas informações permitam futuras análises causais.

Visando melhorar a visualização dos resultados obtidos em relação à origem das manifestações patológicas das assistências técnicas, optou-se por agrupar os resultados em relação ao tipo de origem estudada, conforme pode ser observado na Figura 6. 
Figura 6 - Origem das manifestações patológicas por serviços

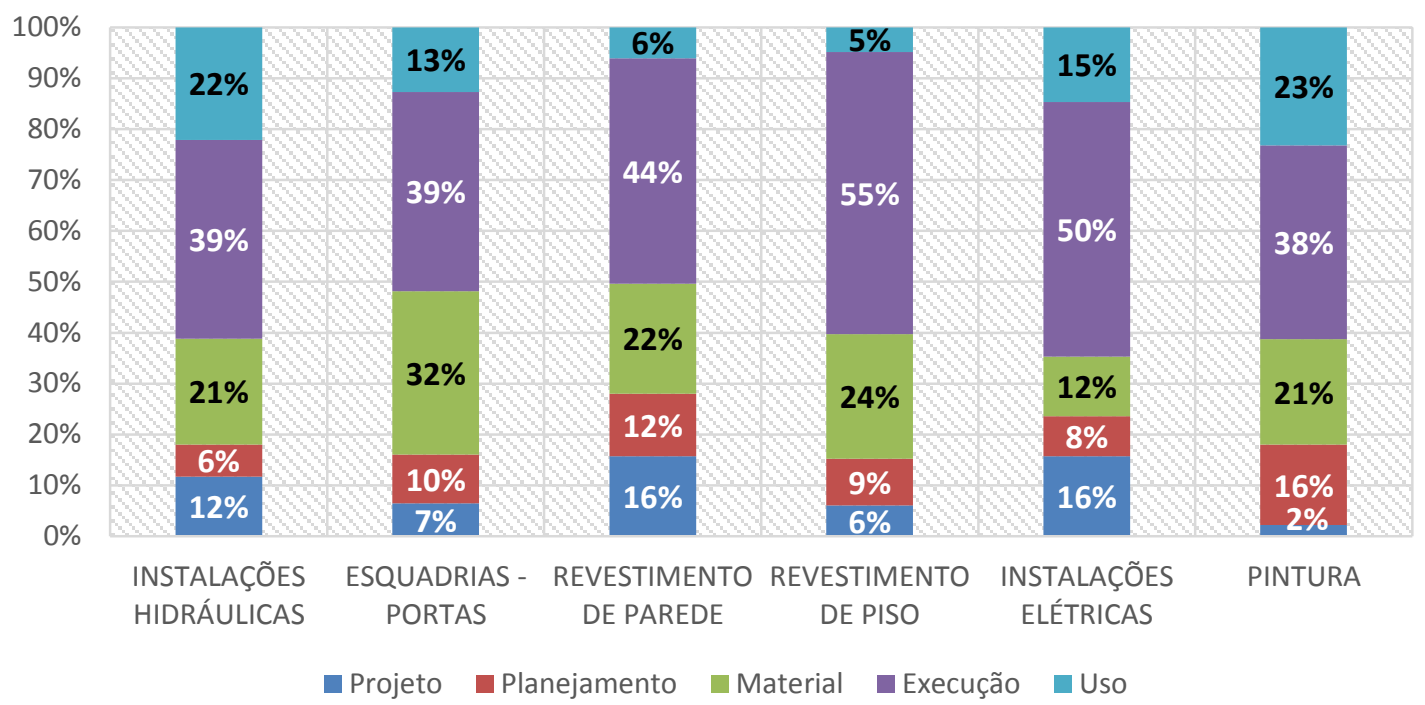

Diante do exposto é possível observar que existe predominância quanto à origem das manifestações patológicas dos serviços com maiores solicitações de assistências técnicas relacionadas à fase de execução dos empreendimentos.

Entre os resultados foi possível verificar que $55 \%$ dos problemas descritos nas solicitações de assistência técnica referente ao serviço de revestimento de piso podem ter relação com a fase de execução do serviço. As instalações elétricas também apresentaram alto índice em relação à origem de suas manifestações patológicas na fase de execução dos serviços, com 50\%, seguido pelos serviços de revestimento de parede, instalações hidráulicas, esquadrias - portas e pintura, com $44 \%, 39 \%, 39 \%$ e $38 \%$ respectivamente.

Já em relação às outras origens das manifestações patológicas detectadas é possível observar algumas alterações quando se analisam os serviços separadamente. As instalações hidráulicas apresentaram como a segunda maior causa de manifestações patológicas serviços com origem na fase de uso do empreendimento, com $22 \%$, seguido pelos serviços com origem nos materiais, com $21 \%$. Esse fato não foi verificado no serviço de esquadrias - portas, que apresentou a segunda maior causa de suas manifestações patológicas com origem nos materiais, com $32 \%$, seguido da fase de uso, com $13 \%$.

Comparativamente ao total observado para o item de projetos (9\%), nos serviços de instalações e revestimento, esse percentual tornou-se um pouco maior, o que confirma a importância que projetos de instalações, projetos de fachada, detalhamento e especificações de projetos quando da minimização de dúvidas na fase de execução que possam resultar em manifestações patológicas na fase de uso dos empreendimentos.

\section{Análise dos resultados da aplicação do FMEA}

As maiores ocorrências de solicitações de assistência técnica foram selecionadas para a aplicação do método do FMEA. O banco de dados de solicitações da empresa $\mathrm{D}$, participante do estudo de caso, foi analisado em relação ao grau de severidade, ao custo e à complexidade de intervenção na correção da manifestação patológica detectada pelo cliente. No total, a aplicação do FMEA foi construída considerando 12 manifestações patológicas de instalações hidrossanitárias, 11 de esquadrias, 7 de revestimentos de parede, 7 de revestimentos de piso, 12 de instalações elétricas, 9 de pintura, 3 de forro de gesso e 2 de revestimento de teto.

Para a análise do FMEA foi desenvolvida uma tabela baseada na metodologia proposta por Miguéis (2010), com adaptações, para se analisarem as manifestações patológicas detectadas no pós-obra. A Tabela 2 ilustra parte da proposta de aplicação do FMEA.

Após o preenchimento da planilha com as ponderações relativas à severidade, ao custo e à complexidade de intervenção foi possível classificar as solicitações de assistências técnicas em prioridade de risco: baixo, moderado, elevado e muito elevado. $\mathrm{O}$ número de ocorrências segundo o grau obtido após a classificação pode ser visualizado na Tabela 3 . 
Tabela 2 - Exemplo da aplicação do FMEA em solicitações de assistência técnica

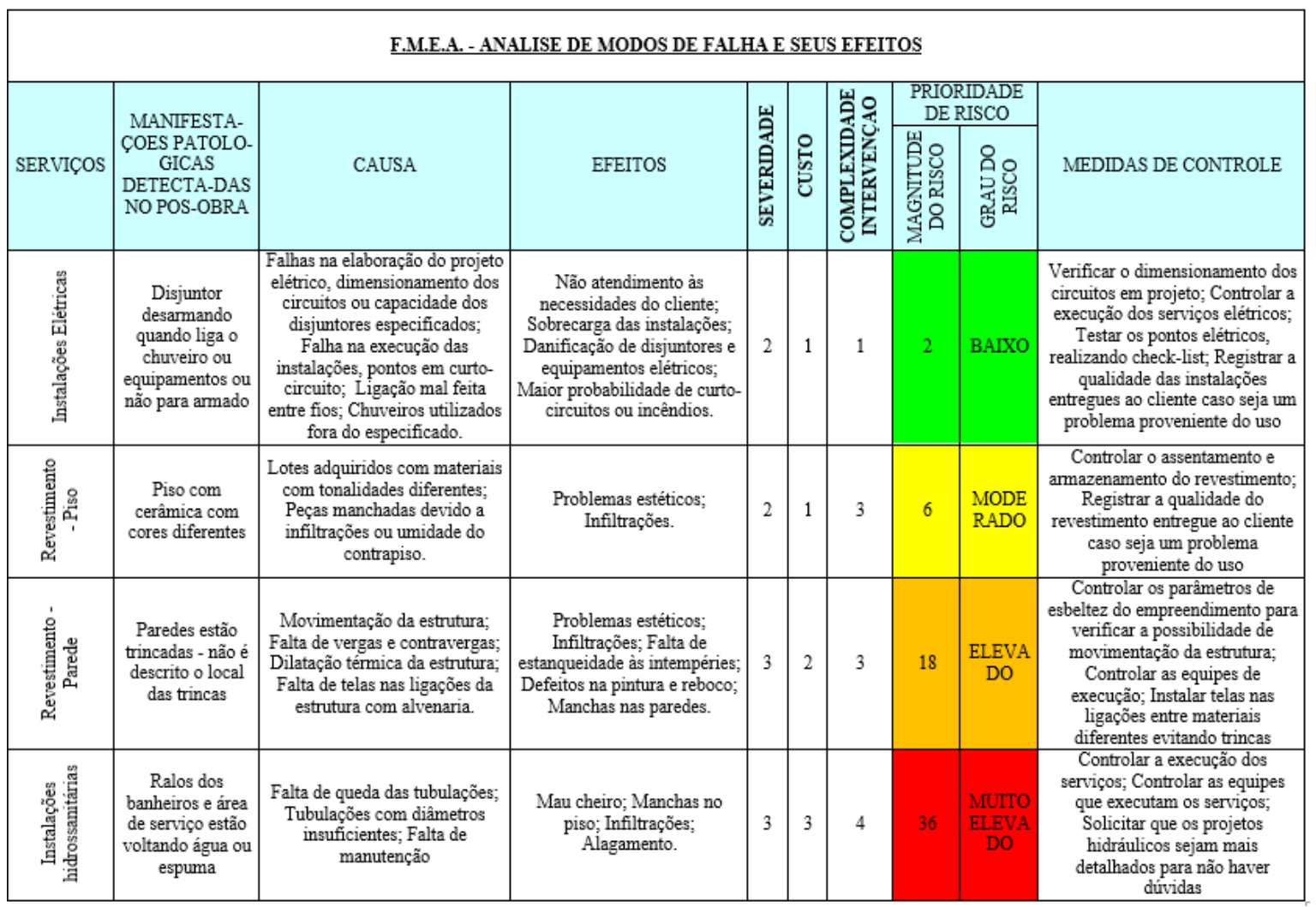

Tabela 3 - Número de ocorrências segundo o grau obtido

\begin{tabular}{|c|c|c|}
\cline { 2 - 3 } \multicolumn{1}{c|}{} & TOTAL & $\%$ \\
\hline PRIORIDADE DE RISCO & 63 & $100 \%$ \\
\hline BAIXO & 31 & $49 \%$ \\
\hline MODERADO & 17 & $27 \%$ \\
\hline ELEVADO & 9 & $14 \%$ \\
\hline MUITO ELEVADO & 6 & $10 \%$ \\
\hline
\end{tabular}

Uma análise relacionando as prioridades de risco com os serviços prestados nas assistências técnicas pode ser observada na Figura 7.

Diante da discriminação por serviços das solicitações de assistências técnicas prestadas é possível verificar que nos serviços referentes às instalações hidrossanitárias, elétricas e esquadrias (portas) a maioria delas refere-se a solicitações de prioridade de risco baixo e moderado. As solicitações com prioridade de risco elevado e muito elevado são provenientes principalmente de solicitações referentes a revestimentos de parede e piso. Tais prioridades são relevantes, pois afetam diretamente mais de um sistema construtivo, assim a complexidade de intervenção é maior, e consequentemente os custos e a severidade do dano ganham maiores proporções.
Dessa forma, esse tipo de análise consegue identificar possíveis pontos que devem ser corrigidos em etapas anteriores ao pós-obra (planejamento, projeto, concepção, execução), para que haja redução dessas manifestações patológicas em empreendimentos futuros.

Cabe ressaltar que a severidade, o custo e a complexidade da intervenção são parâmetros que poderiam ser analisados distintamente, produzindo indicadores para a gestão futura das assistências técnicas. Por outro lado, sendo esses parâmetros analisados em conjunto, por meio do FMEA, gerando então o indicador do grau de prioridade de risco, possibilitam ter uma visão geral da ocorrência em relação ao risco da manifestação patológica e da prioridade no atendimento da mesma e na retroalimentação de suas informações para o sistema produtivo, visando à não ocorrência futura com as mesmas características. 
Figura 7 - Quantidade de solicitações com sua respectiva prioridade de risco por serviço

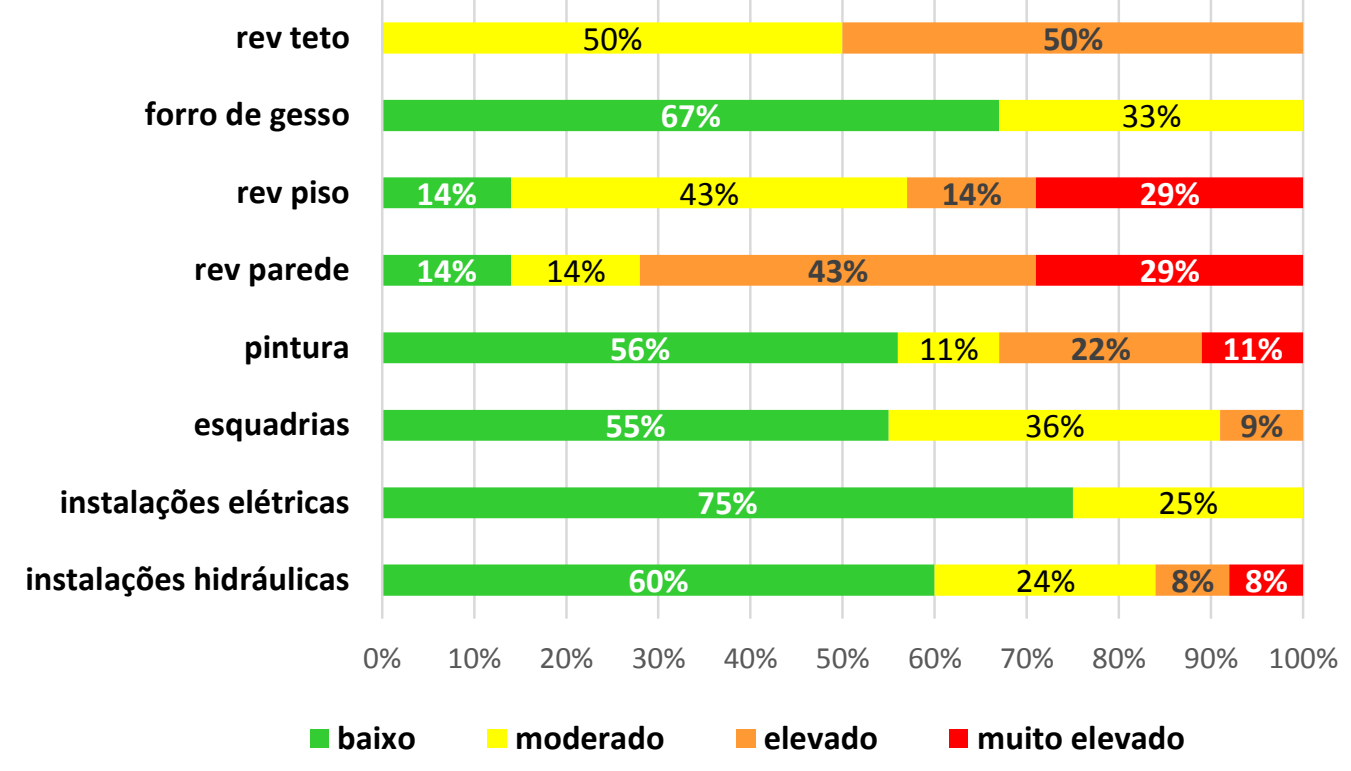

\section{Ferramenta eletrônica para gestão das informações no pós-obra}

A criação de uma ferramenta para empresas construtoras que não possuem uma gestão de informações obtidas no pós-obra visa dar uma contribuição na busca pela melhoria contínua de seus empreendimentos. A Figura 8 ilustra o fluxo de informações que abrange a ferramenta proposta, envolvendo a dinâmica cliente-empresa.

A seguir são apresentadas as rotinas que envolvem a elaboração dessa ferramenta.

\section{Dados de entrada para a ferramenta virtual}

Optou-se em registrar apenas uma solicitação em cada formulário, mesmo que o usuário tenha mais de uma solicitação de assistência técnica. Ainda que seja gerada uma quantidade maior de formulários, as análises referentes ao custo gerado para atender à solicitação, a equipe utilizada, os materiais utilizados, os serviços com maiores solicitações de intervenção, entre outras, poderão ser realizadas sem nenhuma interferência entre serviços. A Figura 9 ilustra parte do formulário para dados de entrada dos registros de assistência técnica, chamado de campo 1 .

No campo 2, intitulado como descrição da ocorrência, é realizado um primeiro filtro, com a identificação do serviço solicitado, manifestação patológica descrita pelo cliente e detalhes necessários da ocorrência. Na Figura 10 pode ser observada parte dessa tabela com os dados de entrada de serviços e dos tipos de manifestações patológicas já inseridos.

$\mathrm{Na}$ sequência do formulário existe o campo "Histórico", destinado a registrar e relatar todas as atividades realizadas pela equipe do departamento pós-obra durante o atendimento às solicitações, envolvendo as etapas de atendimento, datas de execução e responsáveis, visando proporcionar maior controle e facilitar o mapeamento do processo.

Somente a situação classificada como inspeção da solicitação pode ser classificada em procedente ou improcedente. Caso a mesma seja considerada improcedente, o campo "Parecer técnico de chamados improcedentes" deverá obrigatoriamente ser preenchido, dando assim uma justificativa ao fato.

Buscou-se nos campos 4 e 5 do formulário propor formas de registrar os custos com mão de obra e com materiais necessários para o atendimento de cada solicitação. São de grande importância e intencionais ao estudo, pois um dos problemas encontrados nos bancos de dados analisados das empresas construtoras participantes da pesquisa foi a falta de informações relevantes para análises futuras. Entre as informações não registradas pôdese observar que o custo das solicitações foi a informação com maior dificuldade em se registrar.

O campo 6 foi criado pela necessidade de registro de serviços subcontratados. Atualmente vários serviços, tanto na fase de execução quanto na fase de pós-obra, são terceirizados ou subcontratados. 
Figura 8 - Fluxo de informações da ferramenta de gestão proposta

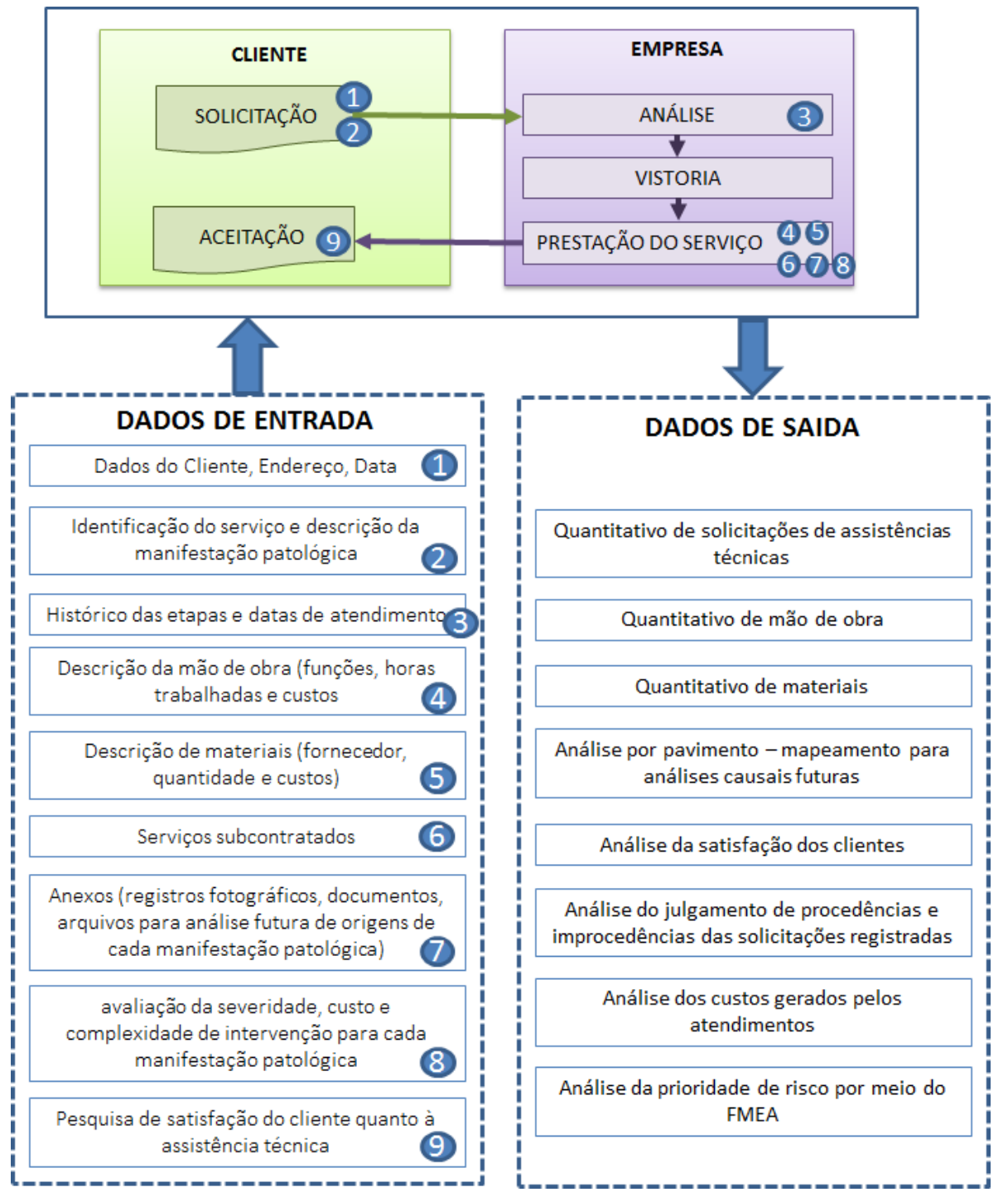

Figura 9 - Formulário de assistência técnica

\begin{tabular}{|c|c|c|c|c|c|}
\hline \multirow{2}{*}{ Logo } & \multicolumn{4}{|c|}{ Formulário de solicitação de assistência técnica - SOS } & \multirow{2}{*}{$\begin{array}{l}\text { SOS - no } \\
\text { Link Anexo }\end{array}$} \\
\hline & & & & Salvar Formulário & \\
\hline \multicolumn{6}{|c|}{ 1. Dados do Cliente } \\
\hline & Cliente: & Raphael Laperche & & & \\
\hline & CPF: & 11122233344 & RG: & 1234567 & \\
\hline & $\begin{array}{l}\text { Telefone (1さ Opção): } \\
\text { E-mail: }\end{array}$ & $\begin{array}{l}9111111 \\
\text { laperche@gmail.com }\end{array}$ & $\begin{array}{l}\text { Telefone (2⿺ Opção): } \\
\text { Profissão: }\end{array}$ & Engenheiro Civil & \\
\hline & Empreendimento: & Solar das Antilhas & Bloco: & A & \\
\hline & Pavimento: & 10 & Apartamento: & 1000 & \\
\hline & Data do Contato: & $26 / 12 / 2012$ & & & \\
\hline
\end{tabular}

No campo 7 é possível anexar fotos ou documentos ao formulário, criando um banco de dados visual das manifestações patológicas detectadas no pós-obra e realizar um "antes e depois" das correções. Na Figura 11 é apresentado o campo de anexos.

O campo 8 refere-se à análise do método de análise de modo de falhas FMEA. Nesse campo é possível ponderar a severidade, o custo e a 
complexidade de intervenção. Dessa ponderação é possível realizar uma avaliação caracterizada como "Prioridade de risco" da manifestação patológica detectada no pós-obra. A prioridade de risco pode variar de 1 a 64 , conforme pode ser observado na Figura 12.

Por fim, o campo 9 do formulário refere-se à análise e pesquisa de satisfação do cliente em relação aos serviços prestados pela empresa construtora no atendimento à solicitação de assistência técnica. Neste campo o cliente pondera de 0,0 a 10,0 a qualidade do atendimento, além de poder fazer observações ou comentários em relação aos serviços prestados.

Figura 10 - Lista de dados de entrada do campo 2 do formulário

\begin{tabular}{|c|c|c|}
\hline & \multicolumn{2}{|c|}{ Listas de Dados de Entrada } \\
\hline $\begin{array}{l}\text { Lista de Serviços } \\
\text { Incluir Serviços nesta lista }\end{array}$ & \multicolumn{2}{|c|}{$\begin{array}{l}\qquad \text { Lista de Tipos de Patologias } \\
\text { Incluir novas classificações de patologias nesta lista, a partir dos serviços da 'Lista de Serviços' }\end{array}$} \\
\hline Serviço & Serviço & Tipo Patologia \\
\hline Alvenaria e Divisórias & Alvenaria e Divisórias & Outros \\
\hline Cobertura & Cobertura & Outros \\
\hline Esquadrias de Madeira & Esquadrias de Madeira & Alizar empenado ou soltando na parede \\
\hline Esquadrias Metálicas & Esquadrias de Madeira & Batente da porta de madeira está soltando \\
\hline Estrutura & Esquadrias de Madeira & Dobradiça da porta soltando \\
\hline Ferragens & Esquadrias de Madeira & Esquadria manchada \\
\hline Forros & Esquadrias de Madeira & Existe um vão entre o portal e a parede \\
\hline Fundação & Esquadrias de Madeira & Fechadura ou maçaneta da porta com defeito, travando, não fecha direito \\
\hline Impermeabilização & Esquadrias de Madeira & Folha da porta está lascada (descascando) ou trincada \\
\hline Instalações Elétricas / Telefônicas / Cabeamento & Esquadrias de Madeira & Outros \\
\hline Instalações Especiais & Esquadrias de Madeira & Porta de vidro desregulada, saindo do trilho \\
\hline Instalações Hidrossanitárias & Esquadrias de Madeira & Porta de vidro ou madeira está pegando no piso ou raspando no batente \\
\hline Outros & Esquadrias de Madeira & Porta está empenada \\
\hline Pintura & Esquadrias de Madeira & Porta instalada com abertura ao contrário \\
\hline Revestimento de Paredes & Esquadrias Metálicas & Outros \\
\hline Revestimento de Piso & Estrutura & Outros \\
\hline Revestimento de Teto & Ferragens & Outros \\
\hline Vidros & Forros & Forro de gesso com trincas \\
\hline
\end{tabular}

Figura 11 - Campo 7 do novo formulário de assistência técnica

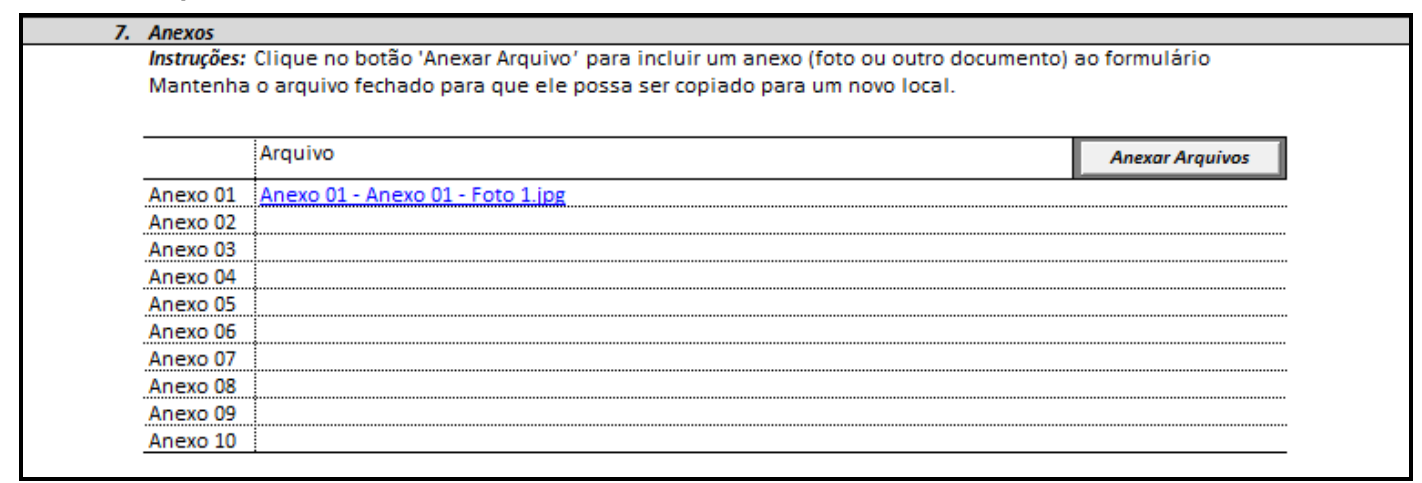

Figura 12 - Campo 8 do novo formulário de assistência técnica

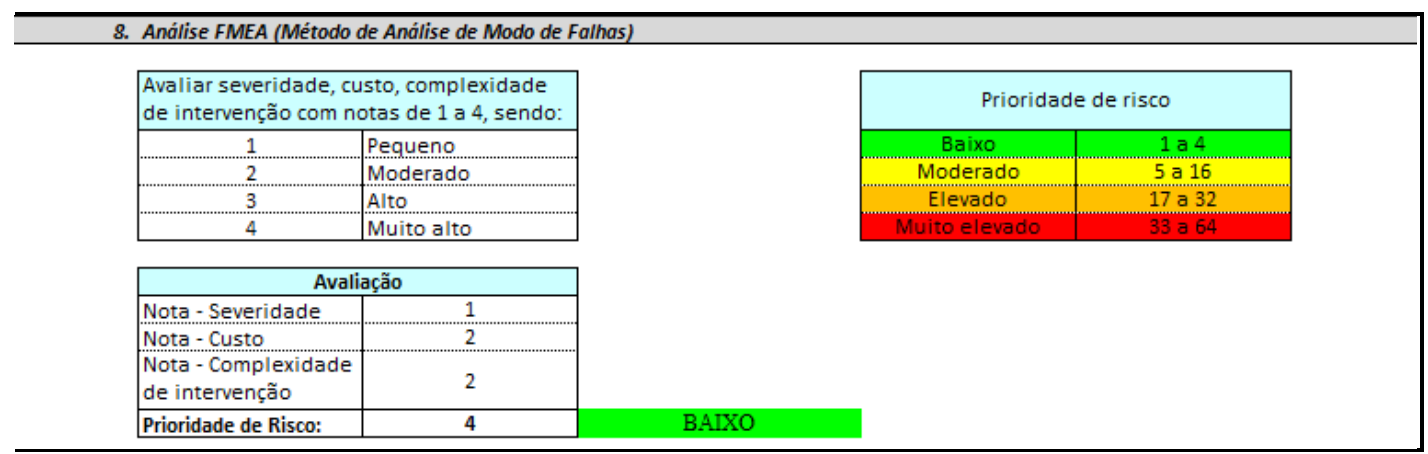




\section{Validação da ferramenta virtual}

$\mathrm{Na}$ empresa D foram abertas 1.607 solicitações de assistências técnicas em 11 empreendimentos, em um período de quatro anos, totalizando assim uma média de aproximadamente 402 solicitações por ano e aproximadamente 37 solicitações por ano por empreendimento.

As informações constantes no banco de dados são analisadas em um outro arquivo, denominado "Análises de dados", elaborado no formato de tabelas dinâmicas que foram divididas em 7 planilhas dispostas em abas diferentes.

A primeira aba do arquivo refere-se à quantidade de assistências técnicas prestadas pela empresa. Toda assistência técnica registrada é computada para o serviço em que a manifestação patológica é selecionada, sendo possível criar um Gráfico de Pareto dinâmico com as informações inseridas no banco de dados.

A análise da tabela dinâmica pode ser compreendida com os filtros destacados do lado direito da Figura 13. As quantidades estão filtradas por ano, e o total geral de cada serviço na sequência.

A aba número 2 refere-se à quantidade de solicitações de mão de obra e de materiais necessários para executar todas as solicitações de assistências técnicas armazenadas no banco de dados.

Pode ser observada na Figura 14 a tabela dinâmica referente às funções e insumos, as quantidades necessárias de cada item, a quantidade de horas trabalhadas no caso da mão de obra discriminada e os custos totais de cada tipo de mão de obra ou material utilizado. Esse tipo de análise permite visualizar qual especialidade de mão de obra está sendo mais utilizada no departamento pós-obra, auxiliando assim a tomada de decisão em relação ao dimensionamento da equipe de assistência técnica.

A aba 3 da planilha refere-se às assistências técnicas por pavimento. Tal análise foi proposta devido ao fato de que algumas manifestações patológicas podem ocorrer com maiores frequências em determinados andares de um empreendimento. Como exemplo pode-se citar o fenômeno da dilatação térmica na laje de cobertura, que provoca trincas e fissuras nos últimos pavimentos, ou então o fenômeno da movimentação da estrutura, que também pode gerar trincas e fissuras e que ocorre com maior frequência nos últimos pavimentos. Com essa análise determinadas manifestações patológicas podem ser mapeadas por pavimento, gerando informações pertinentes para retroalimentar a fase de projetos e de execução dos empreendimentos futuros.

Na sequência a aba 4 da planilha refere-se às notas da pesquisa de satisfação do cliente por serviços prestados. Vários filtros são possíveis de ser construídos em relação à pesquisa de satisfação do cliente, tais como a somatória das notas da pesquisa por serviço e a média das notas gerais recebidas por mês ou por ano.

A quinta aba da planilha de análise dos dados armazenados refere-se ao julgamento de procedência ou improcedência das solicitações de assistências técnicas.

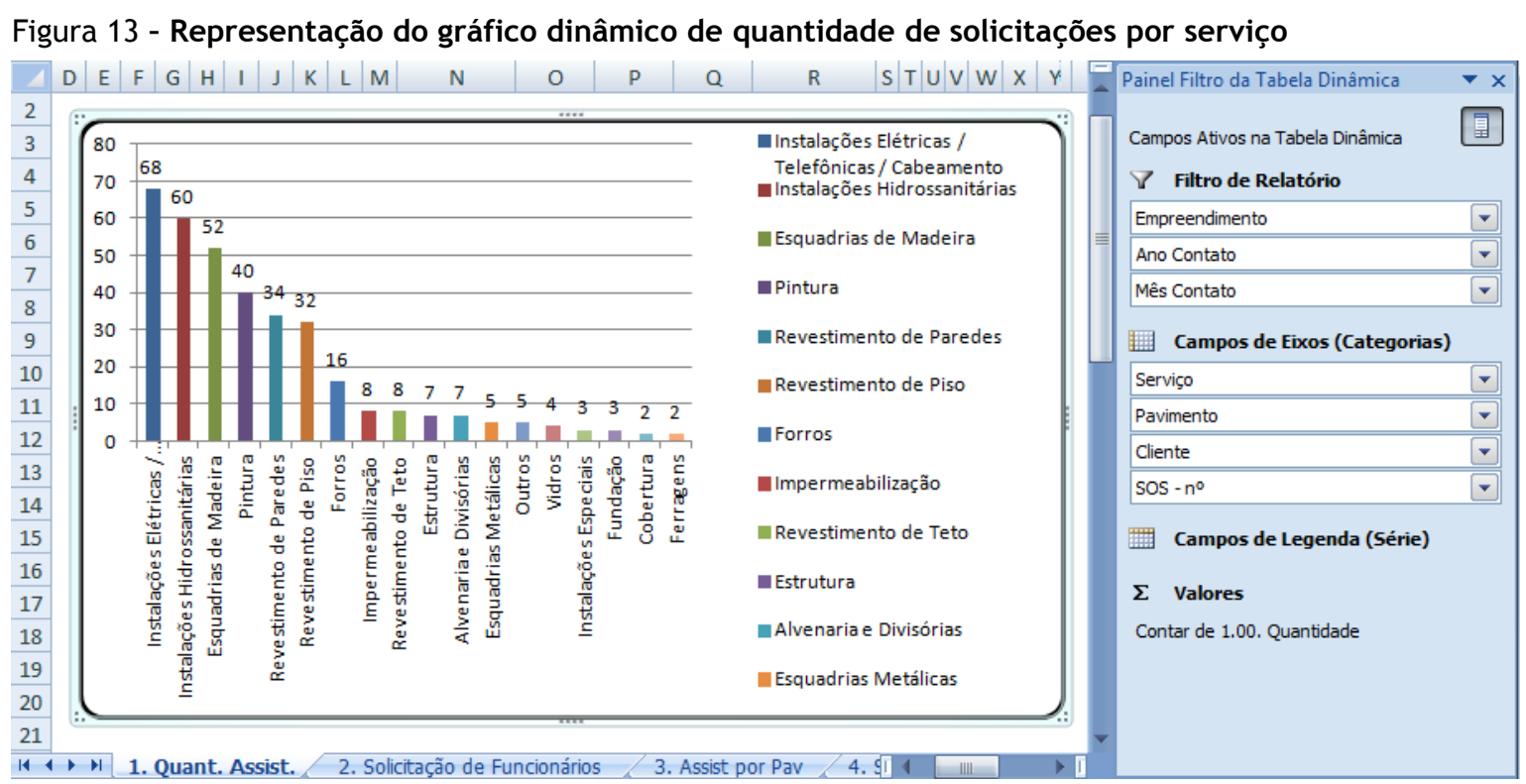


Figura 14 - Quantitativo de solicitação de mão de obra e material das solicitações

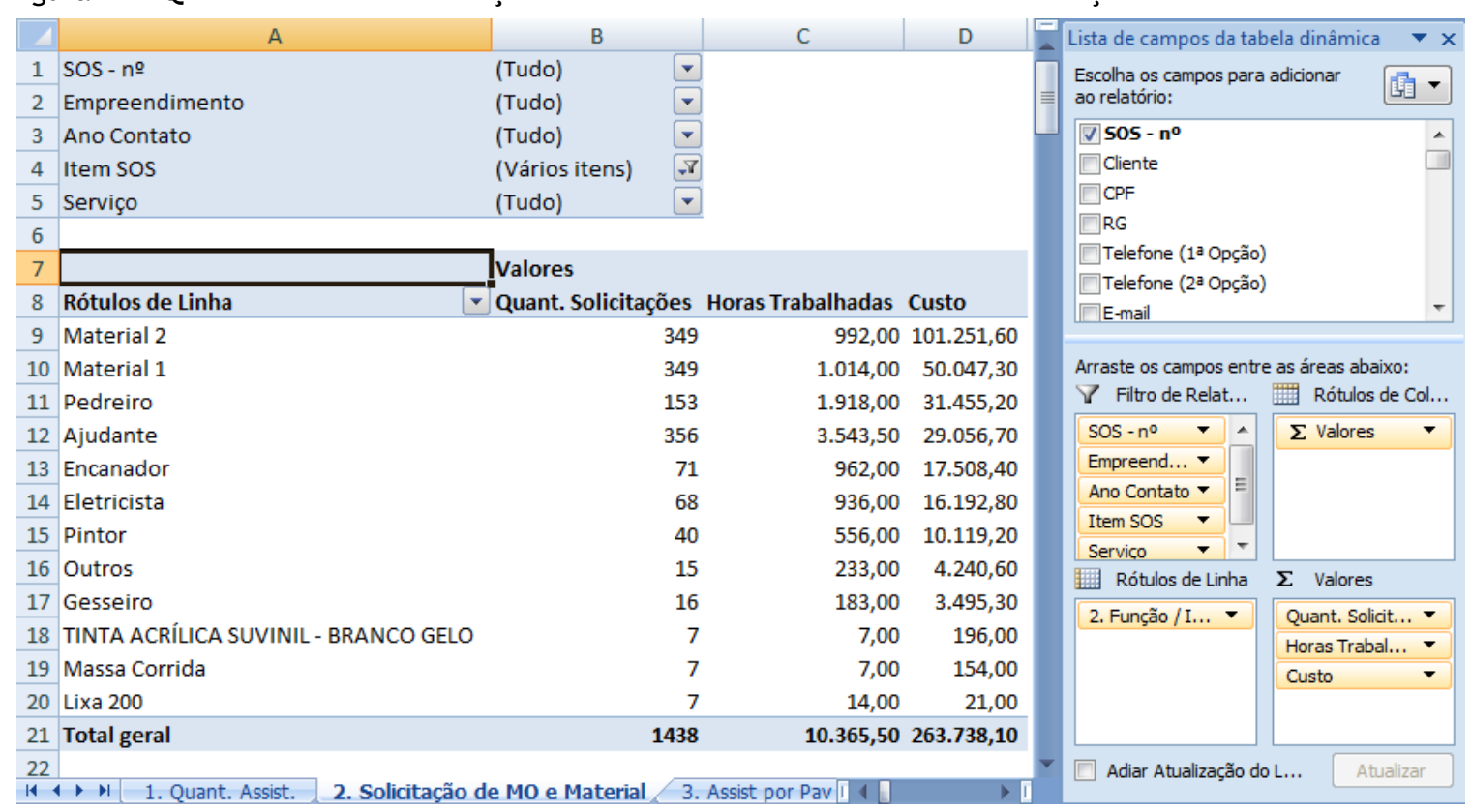

A aba 6 refere-se aos custos gerados pelo atendimento das solicitações de assistências técnicas, podendo ser discriminados por empreendimentos, por data ou por serviços.

A análise das informações referentes aos custos pode ser observada na Figura 15.

Com a tabela dinâmica realizando o agrupamento das informações de custos por serviços é possível por meio dos filtros e da ferramenta do gráfico dinâmico transformar os dados da tabela em um Gráfico de Pareto com os serviços que apresentam maiores custos de intervenção. Tal análise é de grande relevância, pois não necessariamente os serviços com maiores quantidades (análise feita na aba 1) são os serviços com maiores custos de intervenção. É necessário que as análises sejam feitas em conjunto e que as peculiaridades de cada uma delas sejam levadas em consideração para que as informações pertinentes sejam retroalimentadas às etapas anteriores ao pós-obra e para que auxiliem nas tomadas de decisões futuras.

A última aba refere-se à análise de efeitos de modo de falhas (FMEA). Na planilha em evidência na Figura 16 é possível observar que os serviços constantes no formulário foram discriminados com os somatórios da severidade, do custo e da complexidade de intervenção da manifestação patológica durante todo o período de armazenamento do banco de dados.

Conforme a aplicação do FMEA é realizada na análise das manifestações patológicas detectadas no pós-obra, a multiplicação dos parâmetros produz o indicador denominado Prioridade de Risco.

Na tabela dinâmica é proposta outra análise pelo indicador da prioridade de risco para cada serviço, de modo a se obter uma análise relacionando a quantidade com a prioridade de intervenção da falha. Dessa forma é possível ter uma dimensão global da prioridade de risco de um serviço dentro de um conjunto de serviços solicitados. Com a utilização dos filtros da tabela dinâmica é possível visualizar a análise do FMEA em relação a cada manifestação patológica detectada dentro de um serviço.

A análise do FMEA também pode ser representada na forma de gráficos dinâmicos, conforme pode ser observado na Figura 17.

A tabela dinâmica proposta como software de gestão das informações do departamento pós-obra é uma alternativa satisfatória e com baixo custo para empresas que não possuem esse departamento estruturado.

\section{Conclusões}

Em todas as etapas da pesquisa foi possível observar que ainda são poucos os trabalhos que abordam o tema assistência técnica como uma ferramenta de gestão voltada para a melhoria dos processos e produtos na construção civil. A pesquisa contribuiu para a discussão sobre a utilização dos dados de assistências técnicas como forma de prevenção e de identificação de etapas mais propícias a gerar manifestações patológicas futuras. 
Figura 15 - Análise dos custos referentes às solicitações de assistências técnicas

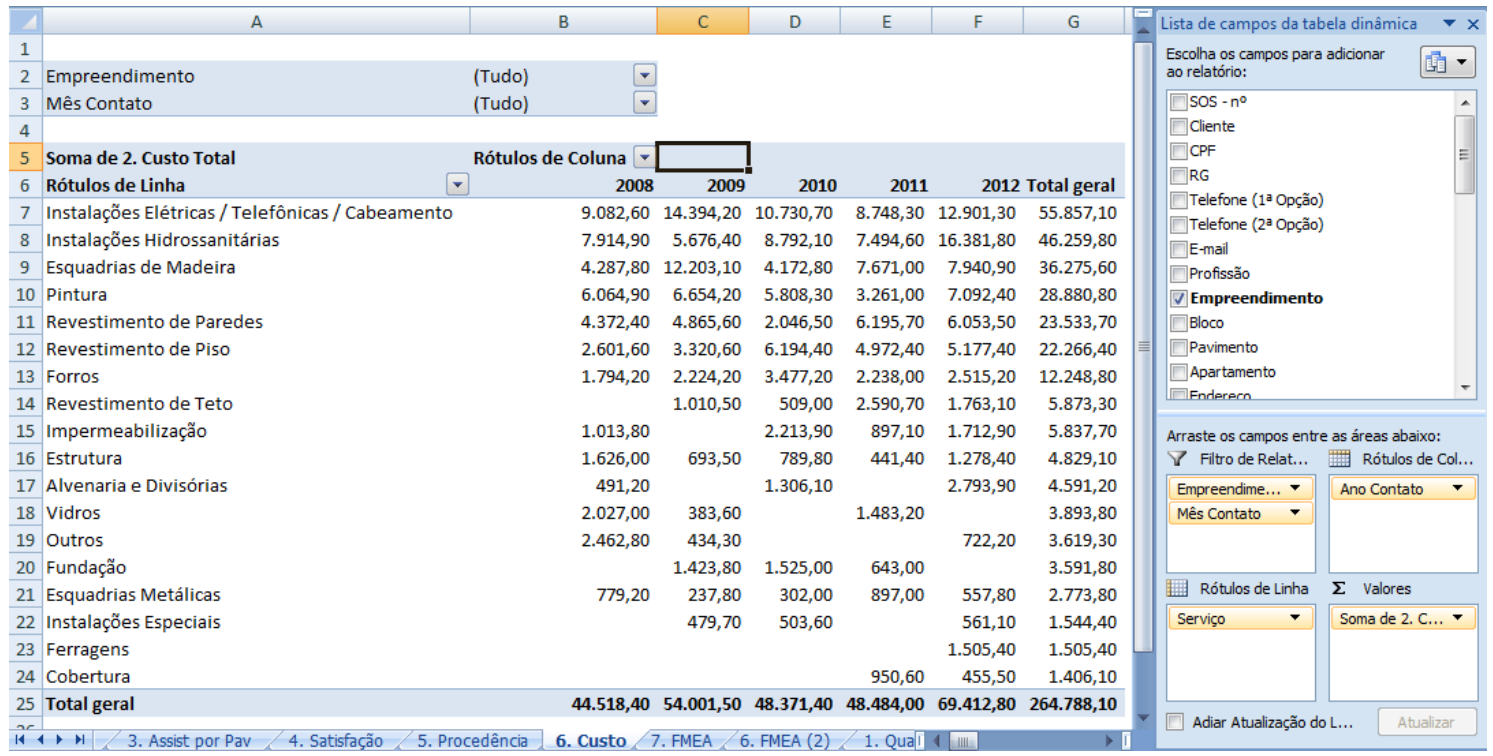

Figura 16 - Análise de efeitos e modo de falhas das solicitações

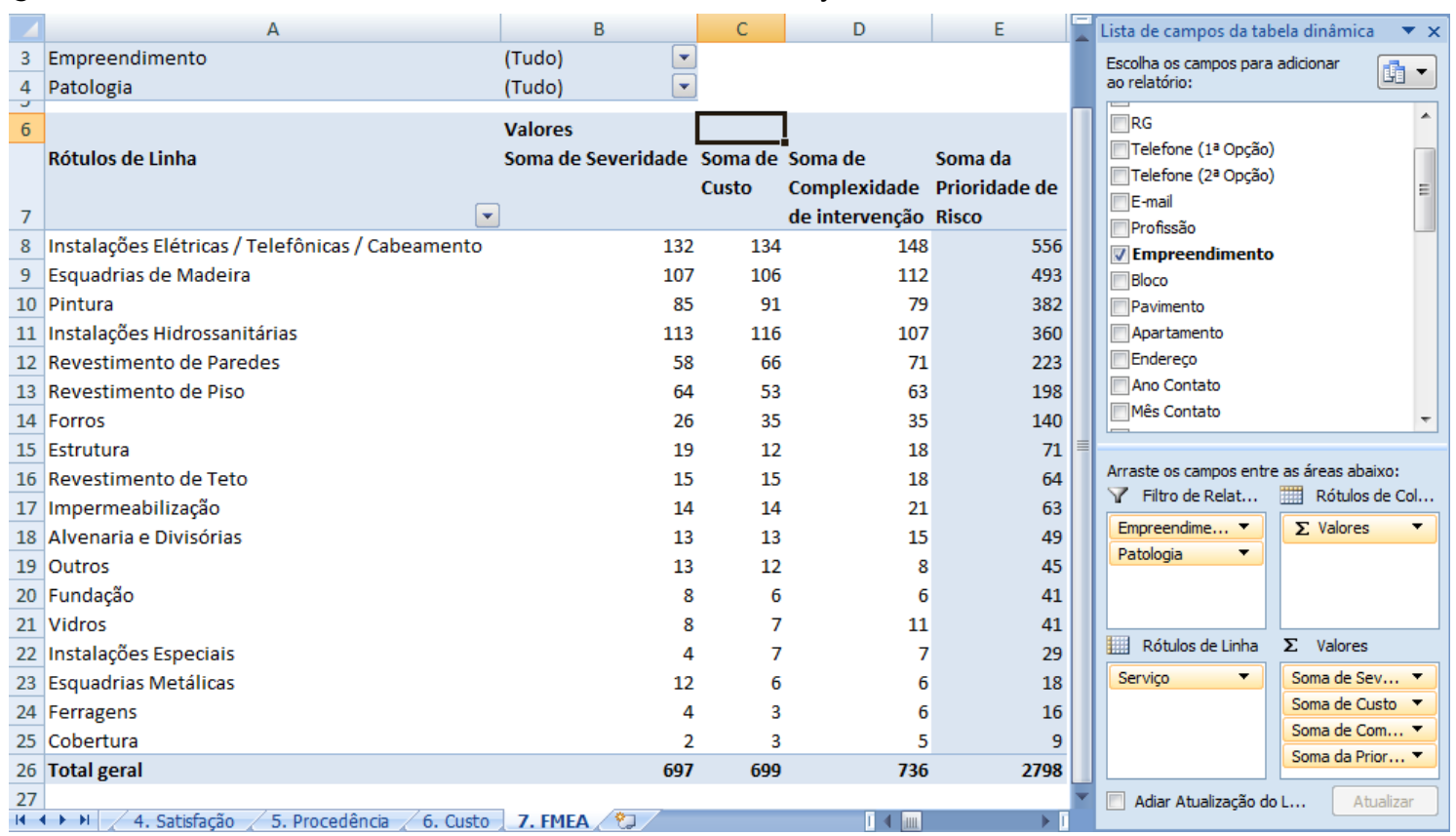


Figura 17 - Gráfico dinâmico representativo do FMEA

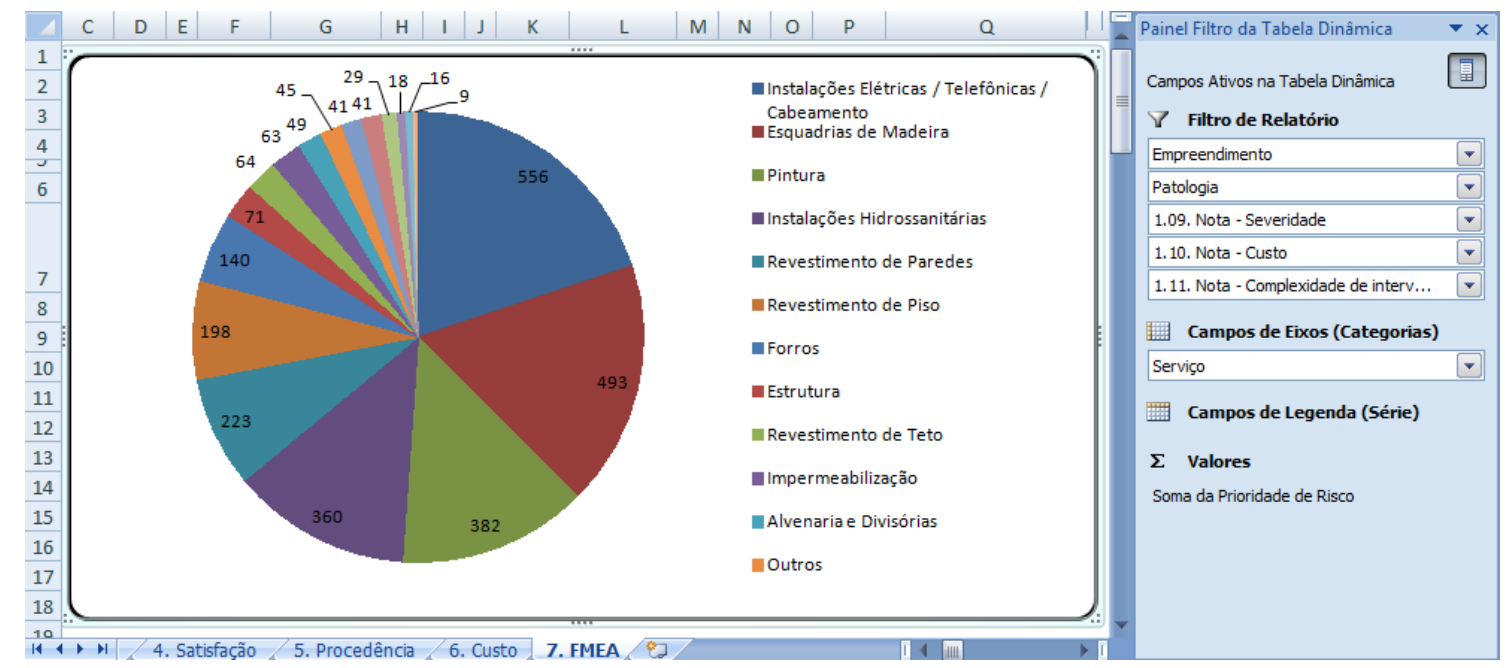

O levantamento de dados envolvendo empresas consolidadas permitiu traçar perfis da maturidade das empresas em relação às informações a serem analisadas no banco de dados de assistências técnicas. Nesta etapa as análises foram fundamentais para visualizar o quão desenvolvido estava o departamento pós-obra das empresas e quanto as informações registradas são limitadas.

Notou-se em um primeiro momento a resistência de algumas construtoras no fornecimento de informações a respeito de seu departamento de pós-obra devido à polêmica que envolve o assunto. As informações de assistências técnicas podem trazer efeitos além dos custos com o atendimento das solicitações, podendo gerar repercussões negativas para a imagem e sobrevivência dessas empresas.

Diante da pouca literatura existente sobre o assunto em questão foi possível verificar por meio dos estudos de caso em profundidade que os principais serviços com maiores incidências de ocorrência de assistências técnicas foram instalações hidrossanitárias, revestimentos de parede, revestimentos de piso e instalações elétricas. Cerca de $80 \%$ das solicitações de assistências técnicas procedentes de ambas as empresas participantes do estudo de caso estão relacionadas diretamente com esses serviços, entre eles os serviços de instalações hidrossanitárias, com uma porcentagem da empresa A de $28 \%$ e da empresa $D$ de $19 \%$, que representam o maior volume de ocorrências de solicitações de assistências técnicas. Tal fato pode ser decorrente de alguns fatores como a maior utilização das instalações, falhas no dimensionamento em projeto e execução das instalações.

Em relação à origem das manifestações patológicas detectadas nas solicitações de assistência técnica foi oportunizado fazer uma análise com profissionais capacitados que ponderaram as origens das ocorrências em uma tentativa de atualizar os poucos dados de referência na literatura. Entre os resultados obtidos foi possível observar que as manifestações patológicas tiveram $44 \%$ das ocorrências relacionadas à fase de execução dos empreendimentos, seguido com $22 \%$ de relacionadas aos materiais empregados; $15 \% \mathrm{com}$ origem na fase de uso e ocupação dos empreendimentos; $10 \%$ relacionadas ao planejamento da obra; e $9 \%$ relacionadas à fase de projeto dos empreendimentos. Esses resultados não confirmaram os dados da literatura que apontam a fase de projeto como a principal etapa do empreendimento responsável por suas falhas no pós-ocupação. Os resultados apontam para a necessidade da continuidade de estudos que possam estabelecer de forma mais precisa a relação causal entre projetos e execução no que concerne às falhas observadas na fase pós-entrega.

A análise dos efeitos e do modo de falhas (FMEA), que, segundo a literatura, pouco tem sido aplicada na indústria da construção civil, pode ser considerada como uma inovação da pesquisa. A técnica FMEA é mais utilizada nas indústrias seriadas, visto que a repetição e a produção em grande escala são predominantes. Para a indústria da construção civil, baseada na execução de produtos únicos com características particulares, a metodologia teve de ser adaptada, propondo índices específicos.

A geração do indicador do grau de prioridade de risco possibilita ter uma visão geral da ocorrência em relação a alguns parâmetros importantes que retratam o risco da manifestação patológica para o empreendimento, a urgência em seu atendimento e 
a retroalimentação de suas informações para o sistema produtivo. A aplicação da técnica ainda permite a categorização por prioridades distintas, quer sejam de severidade, complexidade de intervenção ou custos.

Outro produto final da pesquisa foi o desenvolvimento e validação de uma ferramenta em meio eletrônico que permite a sistematização dos procedimentos. Este modelo buscou apresentar requisitos importantes a serem registrados para que as informações das solicitações de assistências técnicas possam ser utilizadas em empreendimentos futuros, retroalimentando o sistema produtivo e consequentemente diminuindo a incidência de solicitações futuras. A proposição dessa ferramenta contribui para o avanço do conhecimento das propostas de melhorias contínuas nos processos construtivos, uma vez que grande parte das pesquisas nessa área temática se restringe a propostas, em vez da validação de métodos.

Além da originalidade na proposição da ferramenta de gestão, a pesquisa contribui para um melhor fluxo de informações pertinentes às análises de solicitações na grande fase de uso e manutenção das edificações, de modo a propiciar registros corretos e precisos que possam ser úteis na retroalimentação em empreendimentos futuros na forma de diretrizes e decisões gerenciais.

\section{Referências}

ABDELGAWAD, M.; FAYEK, A. R. Risk Management in the Construction Industry Using Combined Fuzzy FMEA and Fuzzy AHP. Journal of Construction Engineering and Management, v. 136, n. 9, p.1028-1036, set. 2010.

AGUIAR, D. C. Avaliação de sistemas de prevenção de falhas em processos de manufatura na indústria automotiva com metodologia de auxílio à decisão. Dissertação (Mestrado em Engenharia Mecânica) - Faculdade de Engenharia, Universidade Estadual Paulista, Guaratinguetá, 2007.

ARDITI, D.; NAWAKORAWIT, M. Issues in Building Maintenance: property managers' perspective. Journal of Architectural Engineering, v. 5, n. 1, mar. 1999.

ASSOCIAÇÃO BRASILEIRA DE NORMAS TÉCNICAS. NBR 5462: Confiabilidade e Mantenabilidade. Rio de Janeiro, 1994.

ASSOCIAÇÃO BRASILEIRA DE NORMAS TÉCNICAS. NBR 5674: manutenção de edificações: requisitos para o sistema de gestão de manutenção. Rio de Janeiro, 2012.
ASSOCIAÇÃO BRASILEIRA DE NORMAS TÉCNICAS NBR 15575: edifícios habitacionais de até cinco pavimentos: desempenho. Rio de Janeiro, 2013.

BAHRAMI, M.; BAZZAZ, D. H.; SAJJADI, S. M. Innovation and Improvements in Project Implementation and Management; Using FMEA Technique. Procedia - Social and Behavioral Sciences, v. 41, p. 418-425, 2012.

BRASIL. Novo Código Civil: exposição de motivos e texto sancionado. 2. ed. atual. Brasília: Senado Federal, Subsecretaria de Edições Técnicas, 2005.

BRITO, J. N. S. Retroalimentação do processo de desenvolvimento de empreendimentos de habitação de interesse social a partir de reclamações de usuários: estudo no Programa de Arrendamento Residencial. Dissertação (Mestrado em Engenharia Civil) - Escola de Engenharia, Universidade Federal do Rio Grande do Sul, Porto Alegre, 2009.

\section{BUILDING STANDARDS INSTITUTION.} Glossary of Maintenance Management Terms in Terotechnology. London: BSI, 1984.

CHEW, M. Y. L.; SILVA, N. de; TAN, P. P. Maintainability of Facades in the Tropics. In: CONFERENCE FOR FACADE DESIGN \& PROCUREMENT, Bath, 2003. Proceedings... Bath: Univ. of Bath, 2003.

CHONG, W. K.; LOW, S. P. Latent Building Defects: causes and design strategies to prevent them. Journal of Performance of Constructed Facilities, v. 20, n. 3, p. 213-221, 2006.

DARDENGO, C. F. R. Identificação de Patologias e Proposição de Diretrizes de Manutenção Preventiva em Edifícios Residenciais Multifamiliares da Cidade de Viçosa - MG. Viçosa, 2010. Dissertação (Mestrado em Engenharia Civil) - Programa de Pós-Graduação em Engenharia Civil, Universidade Federal de Viçosa, Viçosa, 2010.

DAS, S.; CHEW, M. Y. L. Generic Method of Grading Building Defects Using FMECA to Improve Maintainability Decisions. Journal of Performance of Constructed Facilities, v. 25, n. 6, p. 522-533, nov./dec. 2011.

EL-HARAM, M. A.; HORNER, R. L. W. Application of the Principles of ILS to the Development of Cost Effective Maintenance Strategies For Existing Building Stock. Construction Management and Economics, v. 21, n. 3, p. 283-296, 2003. 
FANTINATTI, P. A. P. Ações de Gestão do Conhecimento na Construção Civil: evidências a partir da assistência técnica de uma construtora. Dissertação (Mestrado em Engenharia Civil) Escola de Engenharia, Universidade Estadual de Campinas, Campinas, 2008.

FANTINATTI, P. A. P.; GRANJA, A. D.; MELO, L. C. Captura e Reutilização do Conhecimento na Assistência Técnica Para Obtenção de Vantagens Competitivas. In: SIMPÓSIO BRASILEIRO DE GESTÃO E ECONOMIA DA CONSTRUÇÃO, 5., Campinas, 2007. Anais... Campinas, 2007.

FERNANDES, J. M. R. Proposição de Abordagem Integrada de Métodos da Qualidade Baseada no FMEA. Dissertação (Mestrado em Engenharia de Produção e Sistemas) - Programa de Pós-Graduação em Engenharia de Produção e Sistemas, Pontifícia Universidade Católica do Paraná, Curitiba, 2005.

FERREIRA, L. C. J. Rendimentos e Custos em Actividades de Manutenção de Edifícios: cobertura de edifícios correntes. Dissertação (Mestrado em Engenharia Civil) - Instituto Superior Técnico, Universidade Técnica de Lisboa, Portugal, 2009.

FIESS, J. R. F. et al. Causas da Ocorrência de Manifestações Patológicas em Conjuntos Habitacionais do Estado de São Paulo. In: CONFERÊNCIA LATINO-AMERICANA DE CONSTRUÇÃO SUSTENTÁVEL, 1.; ENCONTRO NACIONAL DE TECNOLOGIA DO AMBIENTE CONSTRUÍDO, 10., São Paulo, 2004. Anais... São Paulo, 2004.

FONG, P. S. W.; WONG, K. Capturing and Reusing Building Maintenance Knowledge: a socio-technical perspective. In: KAZI, A. S. (Ed.). Knowledge Management in the Construction: a socio-technical perspective. Hershey: London: Melbourne: Singapore: Idea Group Publishing, 2005.

GOMIDE, T. L. F. Técnicas de Inspeção e Manutenção Predial: vistorias técnicas, check-up predial, normas comentadas. São Paulo: Pini, 2006.

HELENE, P.; PEREIRA, F. Rehabilitación y Mantenimiento de Estructuras de Concreto. Bogotá: SIKA, 2007.

HENRIQUES, F. M. A. A Noção de Qualidade em Edifícios. In: CONGRESSO NACIONAL DA CONSTRUÇÃO, Lisboa, 2001. Anais... Lisboa, 2001.

KARDEC, A.; NASCIF, N. Manutenção Função Estratégica. Rio de Janeiro: Qualitymark, 2006.
LAURENTI, R. Sistematização de Problemas e Práticas da Análise de Falhas Potenciais no Processo de Desenvolvimento de Produtos. Dissertação (Mestrado em Engenharia de Produção) - Escola de Engenharia, Universidade de São Paulo, São Paulo, 2010.

LEONG, T. K.; ZAKUAN, N.; SAMAN, M. Z. M. Quality Management Maintenance and PracticesTechnical and Non-Technical Approaches. Procedia - Social and Behavioral Sciences, v. 65, n. 3, p. 688-696, 2012.

\section{LICHTENSTEIN, N. B. Patologia das}

Construções. Escola Politécnica da Universidade de São Paulo, Departamento de Engenharia de Construção Civil, Universidade de São Paulo, São Paulo, 1986. Boletim Técnico 06/86.

LIMA, F. A.; CASTILHO, J. C. N. Aspectos da Manutenção dos Equipamentos Científicos da Universidade de Brasília. Dissertação (Especialização) - Faculdade de Economia, Administração, Contabilidade e Ciência da Informação e Documentação, Distrito Federal, 2006.

MARQUES de JESUS, C. R. Análise de Custos Para Reabilitação de Edifícios Para Habitação.. Dissertação (Mestrado em Engenharia Civil) Escola Politécnica, Universidade de São Paulo, São Paulo, 2008.

\section{MIGUÉIS, B. M. C. Aplicação do FMEA a} Sistemas de Construção de Viadutos. Dissertação (Mestrado em Engenharia Civil) Departamento de Engenharia Civil, Universidade de Aveiro, Aveiro, 2010.

PEDRO, J. B.; VILHENA, A.; PAIVA, J. V. Método de Avaliação das Necessidades de Reabilitação: desenvolvimento e aplicação.

Revista Engenharia Civil, Guimarães, v. 39, p. 5 21, 2011.

PEREIRA, N. F. F. B. Gestão e Metodologia da Construção de Um Edifício: sistema integrado de controle de prazos e qualidade. Dissertação (Mestrado em Engenharia Civil) - Instituto Superior Técnico, Universidade Técnica de Lisboa, Lisboa, 2008.

PICCHI, F. A. Oportunidades da Aplicação do Lean Thinking na Construção. Ambiente Construído, Porto Alegre, v. 3, n. 1, p.7-23, jan./mar. 2003.

PUENTE, J. et al. A Decision Support System For Applying Failure Mode and Effects Analysis. International Journal of Quality \& Reliability Management, Bradford, v. 19, n. 2, p. 137-151, 2002. 
RHEE, S. J.; ISHII, K. Using Cost Based FMEA to Enhance Reliability and Serviceability. Department of Mechanical Engineering, Design Division, Stanford University, Stanford, 2003.

SANCHES, I. D. Gestão da Manutenção em EHIS. Dissertação (Mestrado em Arquitetura e Urbanismo) - Escola de Engenharia, Universidade de São Paulo, São Carlos, 2010.

SILVA, S. R. C.; FONSECA, M.; BRITO, J. Metodologia FMEA e Sua Aplicação à Construção de Edifícios. In: ENCONTRO NACIONAL SOBRE QUALIDADE E INOVAÇÃO NA CONSTRUÇÃO, Lisboa, 2006. Anais... Lisboa, 2006.

SIQUEIRA, I. P. Manutenção Centrada na Confiabilidade: manual de implementação. Rio de Janeiro: Qualitymark, 2005.

SITTER, W. R. Costs for Service Life Optmization the "Law of Fives". Comite Euro International du Beton - CEB. Boletim Técnico. Copenhagen, 1984.

SOUZA, D. O. Aplicação de Modelo Adaptado para Análise de Modo de Falhas em uma Construtora Norte-Rio-Grandense. In: ENCONTRO NACIONAL DE ENGENHARIA DE PRODUÇÃO, 33., Salvador, 2013. Anais... Salvador, 2013.
TOZZI, A. R. Desenvolvimento de Um Programa de Verificação de Um Processo de Lançamento de Cabos Com o Auxílio do FMEA. Dissertação (Mestrado em Engenharia Civil) - Escola de Engenharia, Universidade Federal do Rio Grande do Sul, Porto Alegre, 2004.

VAZQUEZ, E. G.; SANTOS, V. A. L. Estudo Estatístico de Patologia na Pós-Entrega de Empreendimentos Imobiliários. In: ENCONTRO NACIONAL DE TECNOLOGIA DO AMBIENTE CONSTRUÍDO, 13., Canela, 2010. Anais... Canela, 2010.

WACLAWOVSKY, E. S. A., BATIZ, E. C. Proposta de Metodologia Para Implementação de Sistemas de Gestão Integrados Como Ferramenta de Apoio no Alcance de Resultados Sustentáveis Para Organizações. In: SIMPÓSIO DE ADMINISTRAÇÃO DA PRODUÇÃO, LOGÍSTICA E OPERAÇÕES

INTERNACIONAIS, 13., São Paulo, 2010. Anais.... São Paulo, 2010.

ZÁRATE, M. et al. Princípios Lean en la Postventa Inmobiliaria. In: ENCUENTRO LATINO-AMERICANO DE GESTIÓN Y ECONOMÍA DE LA CONSTRUCCIÓN, 4., Santiago, 2011. Proceedings... Santiago, 2011.

Daniel Cupertino

Escola de Engenharia Civil | Universidade Federal de Goiás | Av. Universitária, 1488, Setor Universitário | Goiânia - GO - Brasil | CEP 74605-220 | Tel.: (62) 3209-6084 | E-mail: cupertino.daniel@gmail.com

Maria Carolina Gomes de Oliveira Brandstetter

Escola de Engenharia Civil | Universidade Federal de Goiás | E-mail: maria.carolina@uol.com.br

Revista Ambiente Construído

Associação Nacional de Tecnologia do Ambiente Construído

Av. Osvaldo Aranha, $99-3^{\circ}$ andar, Centro

Porto Alegre - RS - Brasil CEP $90035-190$

Telefone: +55 (51) 3308-4084

Fax: +55 (51) 3308-4054

www.seer.ufrgs.br/ambienteconstruido

E-mail: ambienteconstruido@ufrgs.br 